\title{
Propelling Employee Led Innovation in Public Transit Agencies
}

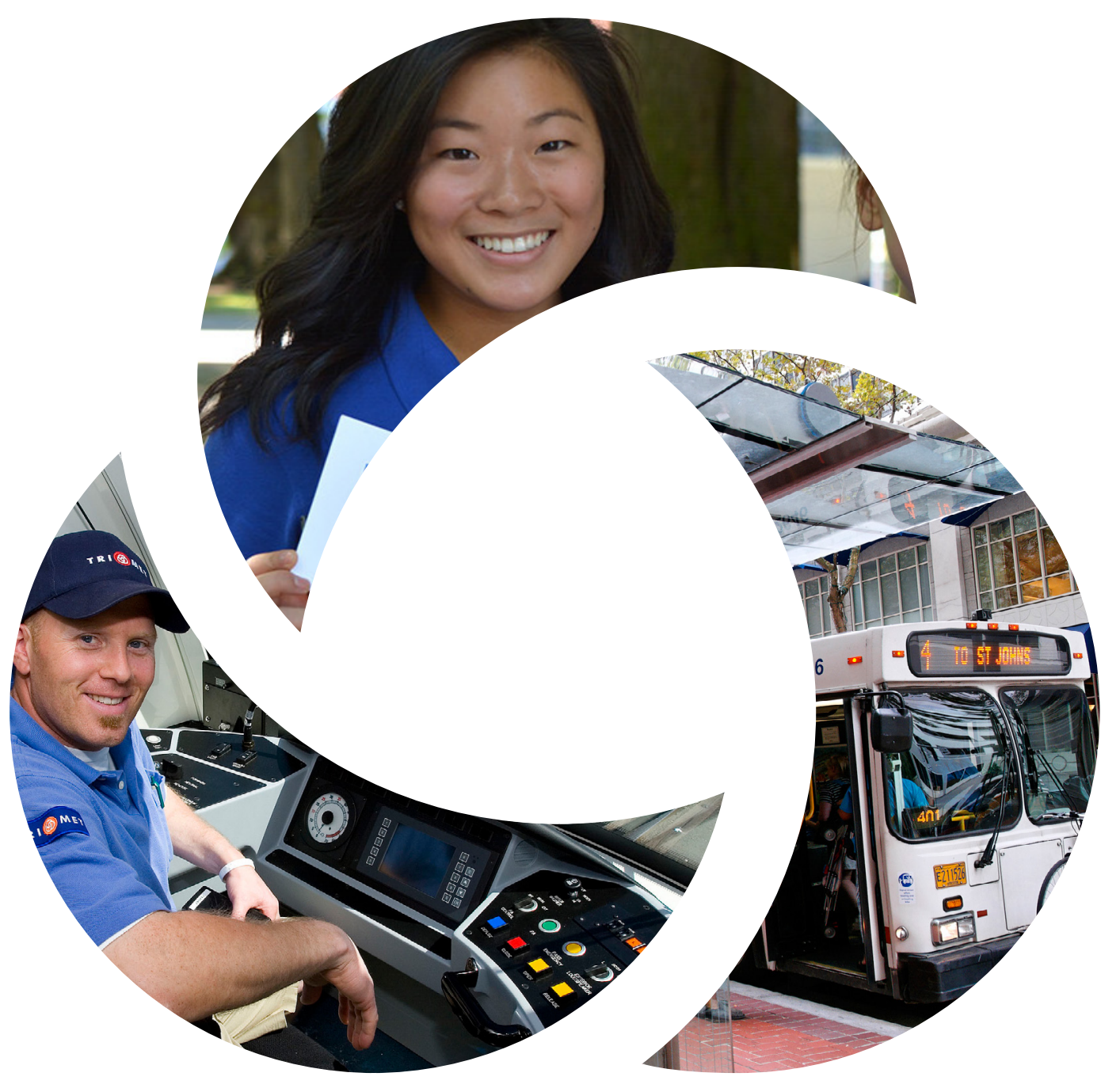

An In-Depth Look at the Tri-County Metropolitan Transportation District (TriMet) of Portland, Oregon 



\title{
Propelling Employee Led Innovation in Public Transit Agencies
}

\author{
by \\ David Cooper, MCIP, RPP \\ BURPl., Urban and Regional Planning, Ryerson University, 2009 \\ A Major Research Project \\ presented to Ryerson University \\ in partial fulfillment of the requirements for the degree of \\ Master of Planning \\ in \\ Urban Development
}

Toronto, Ontario, Canada, 2016

(C) David Cooper 2016 


\section{Author's Declaration for Electronic Submission of a MRP}

I hereby declare that I am the sole author of this MRP. This is a true copy of the MRP, including any required final revisions.

I authorize Ryerson University to lend this MRP to other institutions or individuals for the purpose of scholarly research

I further authorize Ryerson University to reproduce this MRP by photocopying or by other means, in total or in part, at the request of other institutions or individuals for the purpose of scholarly research.

I understand that my MRP may be made electronically available to the public. 


\title{
Propelling Employee Led Innovation in Public Transit Agencies
}

(C) David Cooper MCIP, RPP, 2016

\author{
Master of Planning \\ in \\ Urban Development \\ Ryerson University
}

\begin{abstract}
This paper takes a high level investigation of what elements and considerations are needed to develop a formalized process for idea generation and evaluation for continuous improvement in a major transit agency. A detailed analysis was undertaken of the past and current processes and organizational structures at TriMet (Portland, Oregon's transit agency) to develop an innovation framework to enhance employee engagement and encourage idea generation internally with staff and externally with community partners. This study was informed by a literature review, documentation of case studies on existing continuous improvement and innovation frameworks in four comparable American transit agencies and in person semi structured interviews of TriMet staff from across the agency. A series of twelve recommendations informed by research, staff interviews and analysis discusses how existing processes and structures could be integrated into a formalized innovation framework for the transit agency.
\end{abstract}

Key words: Continuous Improvement, Innovation, American Public Transit Agencies, Employee Engagement, Partnerships 


\section{ACKNOWLEDGEMENTS}

I would like to thank the staff at TriMet for their openness, assistance and great support for this project. I am absolutely thrilled and grateful for their time, genuine interest and amazing kindness in working with me and providing an unique opportunity to take an in depth look at the inner workings of their agency. A special thank you goes to Eric Hesse, Strategic Planning Coordinator at TriMet for working extensively with me on all elements of this project and supporting me through being my second reader for this report. I would also like to thank Neil McFarlane, General Manager of TriMet for his support for allowing me to take an agency wide look at continuous improvement and innovation at TriMet.

Personally for me as a planner, my obligation is to facilitate great things for others, be it in their communities, workplaces and in their personal lives. My hope is that the findings of this report will drive and empower employees from across TriMet to put forward ideas and initiatives that will foster meaningful relationships, create new partnerships and enhance its role in continuing to make Portland a very desirable community to live, work and play.

I am personally grateful for the support of many amazing people who provided me support, guidance and cheered me on through my return to school. This would be my classmates, friends from near and from, my colleagues at the City of Toronto, professors, students and my partner.

A special thank you goes to Professor Nina-Marie Lister for her support throughout my academic journey including being my supervisor of this Major Research Project.

Lastly, I would like to acknowledge my dear friend Lawrence. You left us too soon. I promise to continue your legacy of creating opportunities for others and lighting fires to making great ideas happen from everyone who has a drive and desire to contribute to fostering a collaborate, caring and inclusive community where ever that maybe. 


\section{Table of Contents}

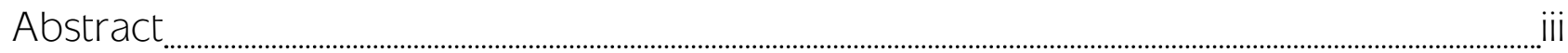

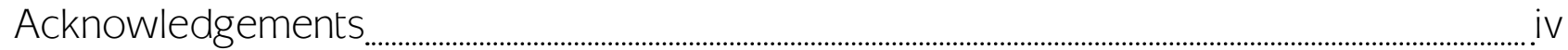

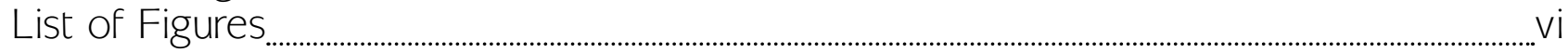

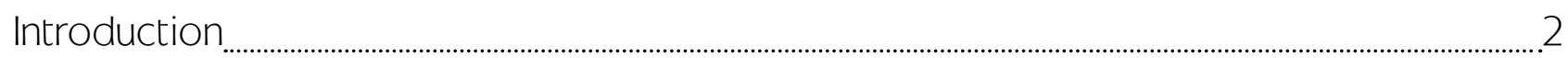

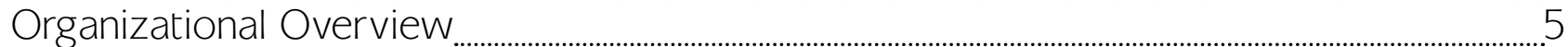

Literature Review 12

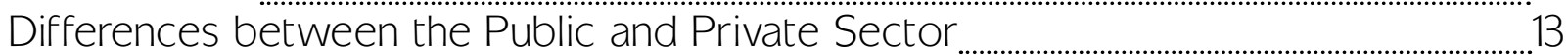

Structure of Transit Agencies ...............................................................................................................................

Strategic Planning in Transit Agencies ……..........................................................................

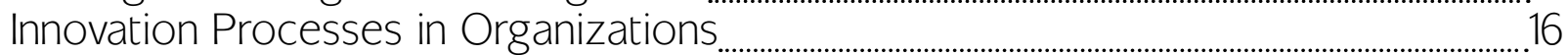

Fostering a Culture of Innovation with Employees .................................................................................. 17

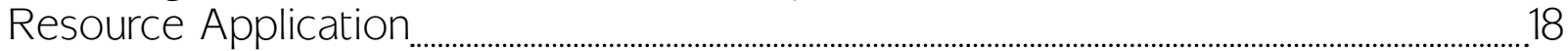

Methodology and Methods .

Literature Review $\ldots$

Case studies $\quad 20$

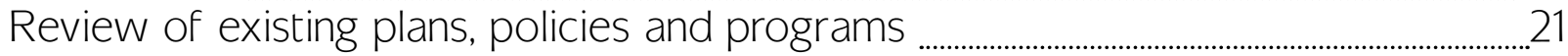

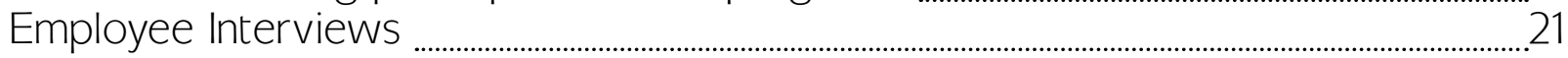

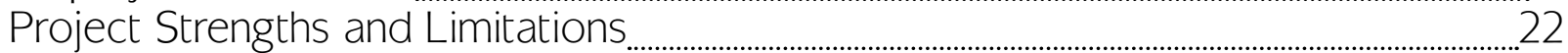

Case Studies $\quad 24$

Los Angeles County Metropolitan Transportation Authority (LA Metro) ................................2 24

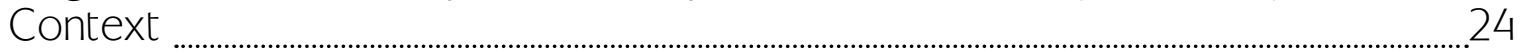

Approach

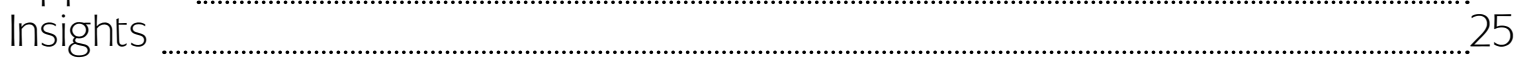

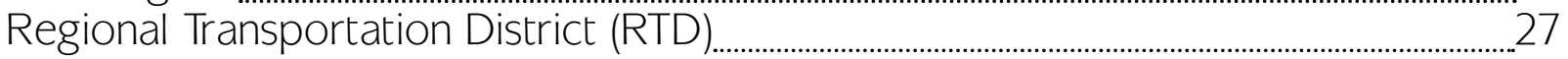

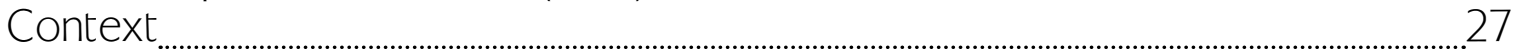

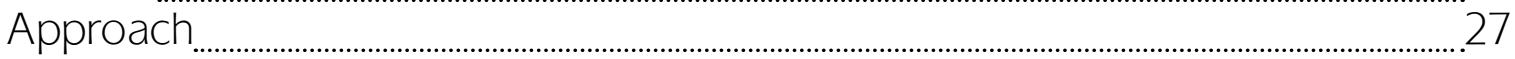

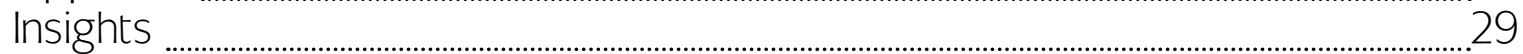

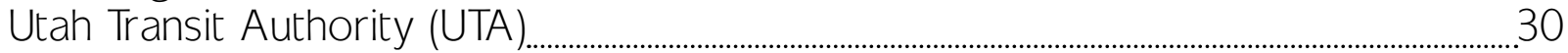

Context

Approach

Insights

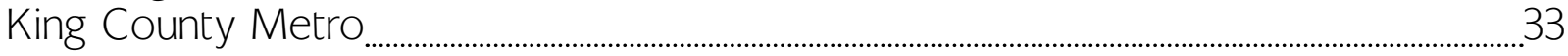

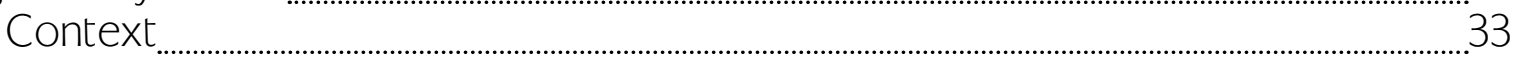

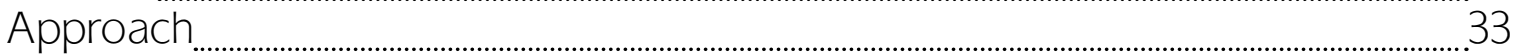

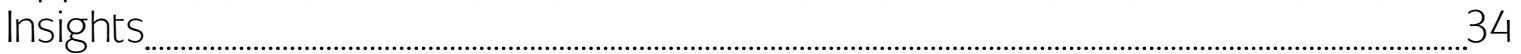

Employee Interview Findings

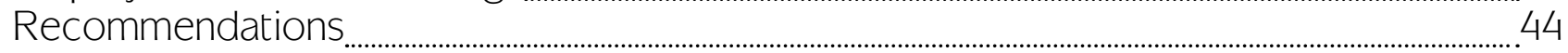

Conclusion $\quad 5 \ldots$

Appendix A: TriMet Organizational Structure .............................................................................................. 51

Appendix B: TriMet Five Year Strategic Goals _........................................................................................... 53

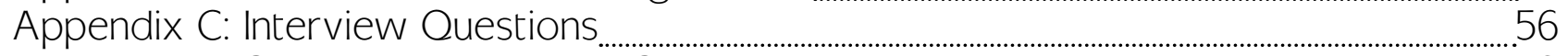

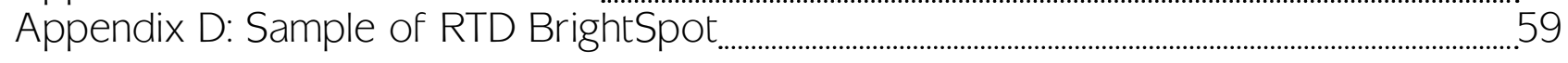

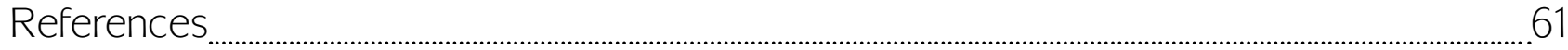




\section{List of Figures}

Figure 1: TriMet's Regional Service Area and Budget ................................................................... 5

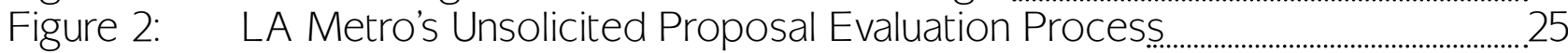

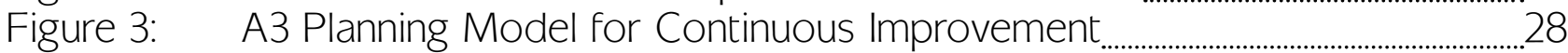

Figure 4: The UTA Way 31 


\subsection{INTRODUCTION}

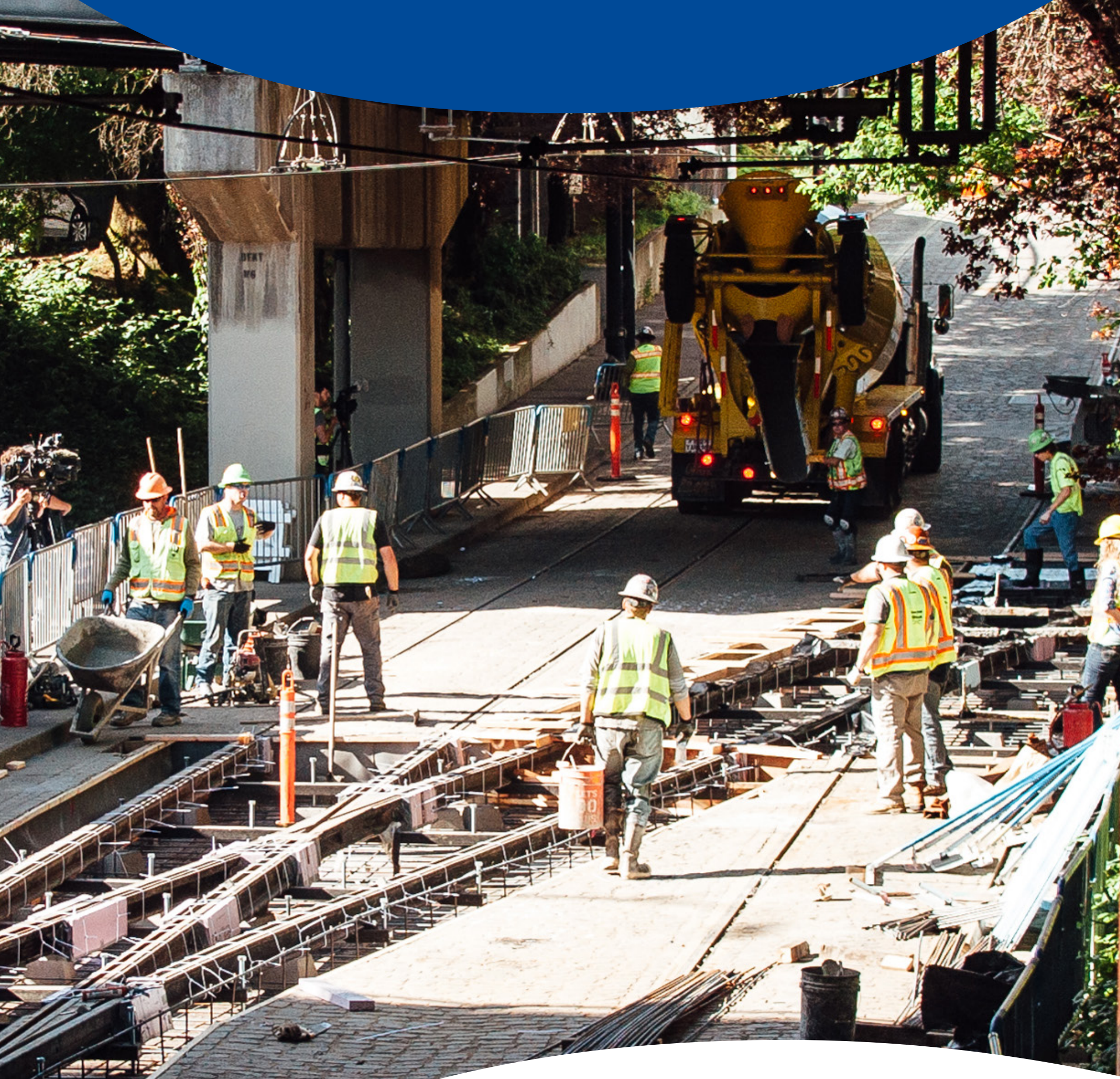

TriMet is at a turning point in its organizational history.

For many years, the organization has been oriented to extensive service expansion with the opening of numerous expansions to the MAX light rail system. The organization is starting to turn its focus to operations and maintaining new assets. TriMet is investing in more state of good repair projects such as the recent track replacement and infrastructure repairs on 1st Avenue. This section of the MAX Light Rail system on the Blue and Red lines has been serving riders for 30 years. 


\section{Introduction}

This paper is a research study designed to conduct a high-level investigation and analysis on the elements needed to create and tailor a continuous improvement and innovation framework for a major transit agency. This study focuses on the process and organizational structures in place at the Tri-County Metropolitan Transportation District (TriMet) of Portland, Oregon, the transit agency for the Portland region. The concept of continuous improvement and innovation processes, initiatives and programs is a relatively new conversation in the public transit industry. In the absence of a formal intake process for ideas, many individuals and groups rely on self-initiative to develop ideas and strategies to bring forward innovative ideas. Many great ideas within transit agencies are cultivated on individual desks. Adopting new ideas without a proper process typically means more work, lending credence to the expression of doing more for less.

There is a structural and psychological misalignment with idea generation and innovation in transit agencies.

Firstly, resources are finite in terms of budgets and staff. Resources are dedicated to core business activities and senior management and political decision-making bodies commonly set organizational priorities. Secondly, in the operational environment, transit agencies are run by standard operating procedures. This is evident in the organizational structures of transit agencies where operating rules and policies are strictly enforced. Operations divisions in transit agencies are structured in a uniformed organization hierarchy. The combination of finite resources with the expectation of adherence to standard operating procedure creates a culture of risk aversion. This can limit employee engagement, by lacking the necessary empowerment for them to contribute ideas that may transform the way transit service is provided.

One of the roles of planners in transit agencies is to spur, facilitate and encourage the public and staff to provide ideas to continuously improve an agency's collective ability to deliver transit service. Planners facilitate and guide discussions through idea generation, strategy development, goal setting and continuous learning. In large transit agencies with thousands of employees, many of which are mobile, it is difficult to engage and integrate the perspectives of all employees, particularly those from the front-line. Operational 


\section{Primary Research Question}

What elements are needed to successfully develop an innovation framework in a public transit system operations environment?

expertise on how to improve functions, process, and policies, particularly from front-line staff, have limited means to go upwards for review, evaluation and analysis in the absence of a centralized continuous improvement and innovation framework.

\section{Objectives}

Determine what structural elements are needed within a transit agency to foster a culture of continuous improvement and innovation

Explore what organizational changes could be required to create an environment of innovation, experimentation within public transit agencies

This study is based primarily on a series of qualitative approaches including a review of key strategies at TriMet, literature review, case studies and employee interviews. Section 2 entails a review and discussion of internal policies and structures at TriMet as they relate to continuous improvement. It has been undertaken to understand existing organizational and decision-making structures. Section 3 covers a multi-disciplinary approach that has been used for the literature review, with research from the fields of strategic planning, change management, corporate culture transformation in the public sector and organizational behavior. Section 4 details the methods utilized for this report. Section 5 documents case studies from four comparable transit agencies on the best practices and processes for internal continuous improvement and innovation. Section 6 provides key findings from the in-person semi-structured interviews of TriMet staff from eleven different sections with staff ranging from Bus Operators to the General Manager focused on understanding the range of considerations from idea generation processes to engagement that would inform a future innovation and continuous improvement framework for the agency.

This paper also makes twelve recommendations on how TriMet can advance towards a culture and framework for continuous improvement and innovation. The final two sections consist of the conclusion and appendices. 


\subsection{Organizational Overview}

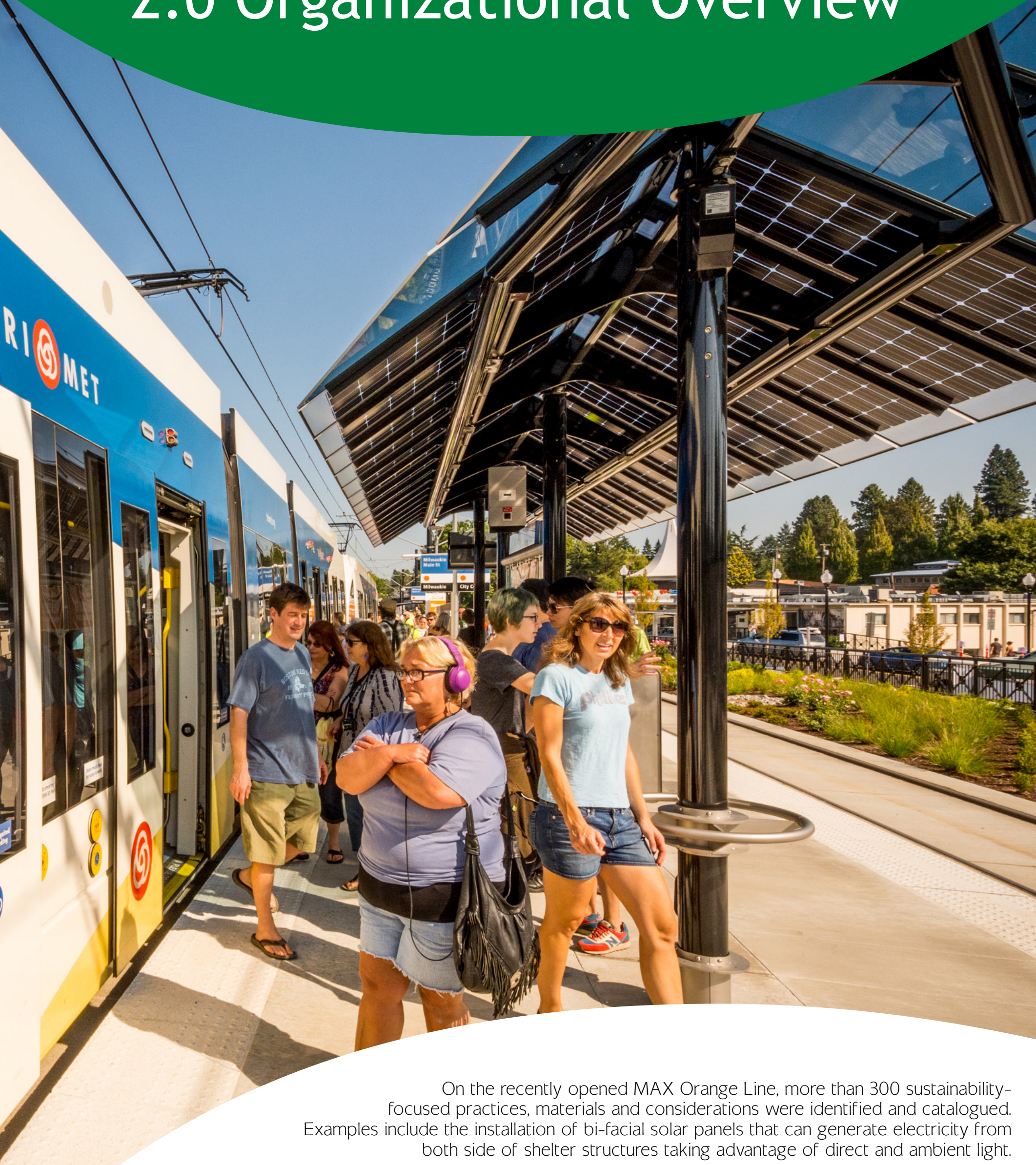




\section{Organizational Overview}

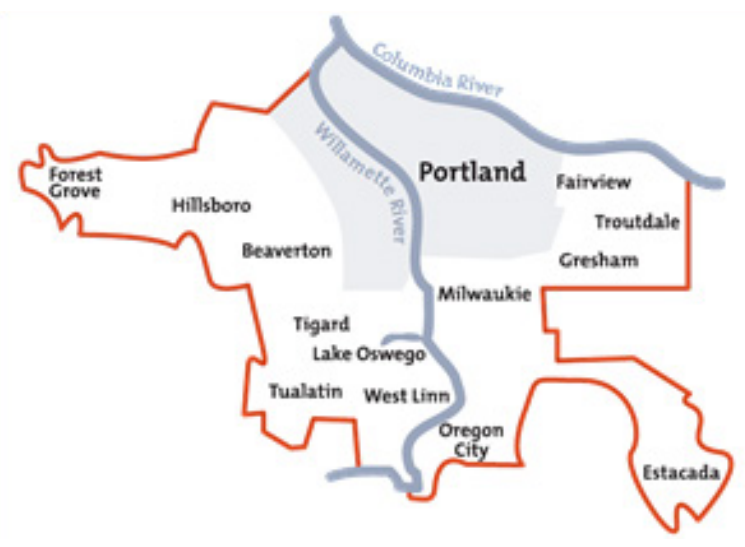

This section of this report documents the organizational structure and review of policies and programs as they relate to continuous improvement and innovation at TriMet. Key analysis was summarized on how existing plans, policies and programs can be integrated into a future continuous improvement framework. Key plans, policies and strategies include corporate strategic goals, budget plans, organizational structure, employee engagement survey, capital project sustainability report and program information on the former agency productivity improvement process.

\section{Agency at a Glance}

TriMet is the transit service provider of conventional bus, light rail, commuter rail and paratransit services in the
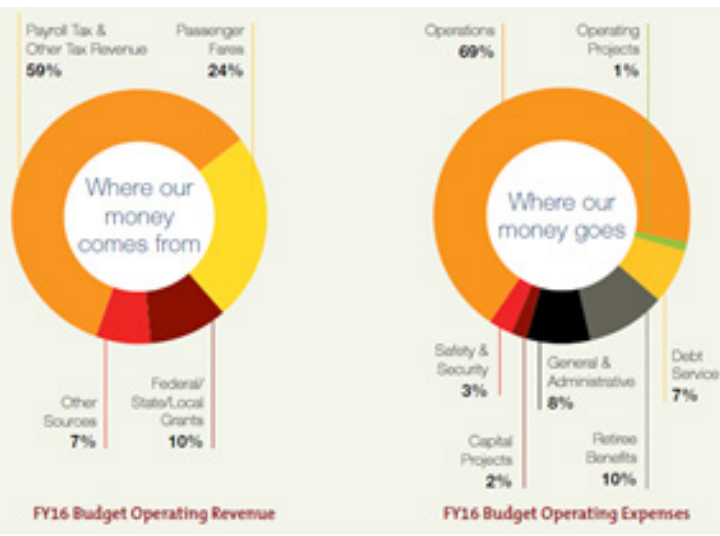

Figure 1: TriMet's Regional Service Area and Budget

Metropolitan Portland region in the state of Oregon. Approximately 315,000 trips are taken on TriMet per weekday equating to 100 million trips taken annually on the transit system. TriMet's service area is 533 Square Miles serving a regional population of 1.5 million residents. The transit network consists of 72 bus routes, 5 light rail lines and one commuter rail service. TriMet's operating budget for the 2016 fiscal year is $\$ 510.5$ million with the overwhelming majority of revenue coming from payroll tax and other tax revenue (59\%) and passenger fares (24\%) (TriMet, 2016a). Figure 1 depicts TriMet's regional service area and budget.

There are approximately 2,700 staff spanning seven operating divisions in Tri-Met located in five operating 
locations with the largest contingent of staff dedicated as Bus and Light Rail operators. TriMet's operating divisions are Public Affairs, Finance and Administration, Legal, Transportation, Safety and Security, Labor Relations and Human Resources, Capital Projects and Maintenance Operations (TriMet, 2016b). Staff representatives from five divisions and the General Manager's Office participated in the semi-structured interviews for this study with key findings reported in Section 6. Appendix A documents the agency's organizational structure as of July 2016.

\section{Review of Continuous Improvement Strategies}

TriMet's Five-Year Action Plan FY2015-2019

TriMet has identified a series of organizational strategic goals that set customer expectations and desire outcomes in customer service, agency finances, organizational capacity building and growth.

TriMet's five-year strategic goals are:

1) Continue to focus on rider needs

2) Ensure financial stability

3) Strengthen the TriMet team

4) Meet the transit needs of the growing region

(Source: TriMet's Five Year Action Plan, FY2015-FY2019 (TriMet, 2015a))
Specific strategies that complement continuous improvement and innovation are identified in TriMet's strategic goals. These strategies involve improving service reliability, increasing service efficiency, providing employees with the tools needed to succeed, engaging employees in finding ways to provide excellent service that results in positive customer experiences and perception, and working with partners to advance projects. Key staff including executive leads, team coordinators and key team members have been identified and tasked with developing and implementing initiatives that advance these highlighted specific strategies (TriMet, 2014). Initiatives that correspond to the identified strategic goals that complement continuous improvement and innovation include implementing new training programs for supervisory staff on managing and influencing change, developing an employee communication strategy to build and sustain a customer focus and evaluating service performance against standards set each year through the Annual Performance Report (TriMet, 2014). TriMet's five-year action plan strategic goals are provided as Appendix B at the end of this report.

\section{Annual Employee Engagement Survey}

TriMet undertakes an annual employee engagement survey soliciting feedback from agency staff on a wide range of topics. The employee engagement 
survey asks questions about alignment with agency goals, benefits, compensation, culture, diversity, feeling valued, individual contributions, job satisfaction, manager effectiveness, teamwork, trust in senior leaders and trust in co-workers. The overall staff response rate was 30\% with a greater response rate from non-union staff (84.6\%) compared to union staff (19.8\%). There is a strong desire of staff to promote continuous improvement where $88 \%$ of respondents reported favorably that they are thinking of better ways of doing his/her job better. In terms of group collaboration, 57\% of respondents reported favorably that their team effectively collaborates leveraging individual strengths. There is room for improvement within the agency, where 29\% of respondents responded favorably that if they contributed to the transit agency's success, he/she knows that it will be recognized (TriMet, 2016c).

\section{Portland-Milwaukie Light Rail Transit}

Project Sustainability Report

TriMet celebrated the opening of new 7.3 mile, 10 station Portland-Milwaukie Light Rail Transit Line, commonly referred to as the "Orange Line" on September 12, 2015. In semi-structured interviews of TriMet staff, staff saw the sustainability report as an excellent set of initiatives that were innovative in terms of infrastructure design and partnerships. In absence of transit industry-wide standards for sustainability, TriMet staff informally applied two sustainable infrastructure ratings systems to the project: The Envision Sustainable Infrastructure Rating System and the Infrastructure Voluntary Evaluation Sustainability Tool (INVEST) 1.0. In this light rail capital project, more than 300 sustainability-focused practices, materials and considerations were identified and catalogued (TriMet, 2015b). Examples include the installation of bi-facial solar panels that can generate electricity from both side of shelter structures taking advantage of direct and ambient light and the installation of the first green trackway in the United States. TriMet fostered partnerships with external agencies such as the Transportation Research and Education Center (TREC) at Portland State University with providing data from newly installed electric vehicle parking stations at two light rail transit stations to study electric vehicle travel and utilization patterns (TriMet, 2015b).

\section{Staff Identified Innovation at TriMet}

In the Semi-Structured interviews, staff were asked questions pertaining to the agency's experiences with experimentation, pilot projects and partnerships. Staff identified two successful innovations including the development of the first mobile fare payment app sourced through the agency's unsolicited proposal process, and releasing open data 
to provide real-time schedule information to customers.

A local Portland software company "GlobeSherpa", now "moovel North America", engaged TriMet through the unsolicited proposal process to develop, implement and maintain the agency's mobile fare payment app. TriMet conducted the three-step evaluation process for unsolicited proposals which entailed an initial review and evaluation of the proposal, a publication to determine sole source, and a secondary review of required supplementary materials (TriMet, n.d.). The app was launched for public use in 2012. TriMet provides moovel a share of the revenue sales transacted through the app and maintained the source code for redundancy and development reasons. Moovel has now expanded its mobile ticketing app to other major U.S. transit agencies such as the Chicago Transit Authority and San Francisco Muni (Moovel North America, 2016).

TriMet was the first transit agency in the United States to release open data information on transit routes, schedules and real time vehicle information, which can be downloaded for analysis and integrated into applications. TriMet was the first transit agency to collaborate with Google Transit to create a General Transit Feed Specification to allow for trip planning on Google Maps. Now, nearly 500 transit agencies are publishing open data for trip planning and real-time customer information (Institute for Sustainable Communities, 2016).

Productivity Improvement Process (PIP)

Staff frequently discussed TriMet's former Productivity Improvement Process (PIP) when discussing their involvement and expertise in continuous improvement initiatives within the agency. The PIP program launched in December 1999 as a program tailored to employee driven innovation and continuous improvement. PIP recognized that frontline employees need to be successful in removing day-to-day frustrations, that management can facilitate the exploration of opportunities to create efficiencies and ensure that the agency is leveraging existing resources as much as possible to expand transit service for the region's residents (TriMet, 2003).

The PIP program was deployed into various working areas throughout the agency utilizing a six-step process. Initial divisions that participated in PIP included maintenance and transportation through on-street supervisors and fare inspectors. According to TriMet (2003) documentation on this process, PIP consisted of the following six steps:

Step 1 - When PIP is introduced to a division, a working group identifies a process or area where improvements can be made. 


\section{The six PIP goals for continuous improvement}

\section{Maximizing use of existing resources to increase service}

Creating effective employee forums that draw out the best thinking of staff from all levels, especially those closest to the work

Working in full partnership with the Union to implement system efficiencies

Providing challenging and rewarding work, with opportunities for professional growth

Sustaining a work environment that continually finds ways to improve systems and processes, and;

Leveraging and capitalizing on new technologies

Step 2 - The group sets goals and measurements

Step 3 - An employee team forms around the initiative and engages other affected employees in discussion and problem solving. Teams use specific techniques such as "process mapping."

Step 4 - Employees begin to create the new process

Step 5 - When the new process is completed, teams implement improvements and evaluate effectiveness

Step 6 - After the PIP initiative experience, employees take what they have learned and look for further areas of improvement. Productivity becomes a way of thinking and working (TriMet, 2003).

After meetings with 300 staff in the first six months of the PIP process, five specific PIP initiatives were announced - Attendance/Overtime/Extra Board, Bus Maintenance, Field Presence, Inventory/Stores and Rail Maintenance and team leads were appointed to each team. Team leads and divisional staff composing of front-line employees received training in the PIP process, analyzed data and recommendations from the initial assessment of processes from the original PIP leadership team, prioritized issues and commenced work. The composition of PIP's 
front-line teams is similar to the present day practice of formulating Continuous Improvement Teams.

Present day Continuous Improvement Teams are deployed to review and generate recommendations informed by analyzing data and employee engagement on ad hoc issues of concern within the agency. Continuous Improvement Teams will be discussed more in detail in Section 6 employee interviews. Strategic management oversight to the PIP process was structured through the creation of a PIP Steering Committee composed of the TriMet General Manager, General Counsel and the Executive Directors of Operations, Finance and Capital Projects (TriMet, 2003).

Within three years of the commencement of the PIP program, cost savings and efficiencies were reported amongst almost every division across TriMet. Efforts undertaken through the PIP program resulted in $\$ 10$ Million in operating and capital dollar savings between fiscal years 2001-2002. Highlights of the initiatives and savings created by the PIP program include:

Utilizing agency-wide contracts for business supplies, negotiating discounts with key suppliers and using e-commerce websites for surplus disposal resulting in $\$ 200,000$ in savings
Reorganizing of the Center Street bus yard to accommodate and service 33 additional buses which increased operating efficiency and decreased dead-heading time

Reducing electricity costs by 20 percent by retrofitting lighting along MAX light-rail right-of-way saving $\$ 150,000$

Adopting 'just-in-time' inventory practices modeled after Boeing and reducing bus part inventory value from \$4.1 Million to \$2.5 Million, freeing up money previously allocated to unused bus part inventory (TriMet, 2002).

During the semi-structured interviews with staff, the PIP program was spoken about very highly, even with one staff member noting that when staff speak about their accomplishments at TriMet, many of them are connected with initiatives originated through the PIP program. It was unclear from discussions with staff and from provided documentation from the PIP program on when and why the program concluded. 


\section{Literature Review}

This literature review discusses the various elements that are required to incorporate a culture of innovation and continuous improvement into public transit agencies. This review will also explore how literature and research on innovation has identified opportunities and constraints within the typical organizational structure of transit agencies, and how to orient transit agencies to foster a culture of continuous improvement and innovation. For the purposes of research, discussion with TriMet staff in focus group interviews and the basis of recommendation, this study focuses on the ability of transit agencies to encourage process innovation. Bason (2010) identifies process innovation, defined as the way structures, work processes and routines are organized, and how changing these factors may increase the value of the organization's outputs. When organizations are investigating ways to optimize workflow and streamline case management, this is process innovation. Transit agencies also use the complementary term "continuous improvement" when outlining efforts that promote innovation in their agencies. The Utah Transit Authority defines continuous improvement as "an ongoing effort to improve products, services or processes (Utah Transit
Authority, 2016a). These efforts can be incremental improvement over time or breakthrough improvement all at once. Immersing employee engagement and empowerment into process innovation and continuous improvement is a key objective of this study.

Academic literature elucidates the differences and complementary outcomes between the public and private sector and what elements are necessary to drive process innovation in organizations. Specifically, academic literature explores how to innovate within government. Discussion related to the structure of public transit agencies has been augmented through research completed by the Transit Cooperative Research Program funded through the Federal Transit Administration in the United States. Information and discussion provided through case studies of other comparable transit agencies in later sections of this report assist with discussing innovative practices and orientations in public transit agencies. A range of other sources (books, articles and websites) has also been used to inform the literature review. Findings from the literature review informed the research methods and study recommendations. 


\section{Differences between the Public and Private Sector}

How the public and private sectors respond to the concept of innovation and continuous improvement is related to the mandate and outcomes of each sector. The first key difference between the public and private sector is that organizational objectives tend to be multi-disciplinary in the public sector, specifically with collective goals of equity, efficiency, safety and fairness. Meanwhile, the private sector primarily focuses on maximizing profits and meeting individual goals (Shockley, Frank \& Stough, 2008; Transit Cooperative Research Program, 2005; Needham, 2006; Adams, 2015). Decision making in the public sector is typically done at an executive level (e.g., boards, senior staff) but is increasingly delegating elements of decision making to a larger, diverse of set of stakeholders. In terms of accountability, the public sector is accountable to the public while the private sector is accountable to shareholders (Shockley et al., 2008; Transit Cooperative Research Program, 2005). In terms of customer response within each sector, customers in the private sector can make their preferences known by not choosing a service or purchasing a product; in contrast, this is not possible in the public sector, where services are typically offered as a monopoly (Fountain, 2001; Adams, 2015)
Former Commissioner of Transportation for the cities of Chicago and Washington Gabe Klein (2015) has discussed the evolving role of local governments increasingly becoming agents of innovation and experimentation. The difference between the public and private sector in terms of innovation stems from divergent cultures, lack of knowledge about the opposite sectors' perspectives and an ongoing skepticism of the capacity that governments can efficiently serve taxpayers. The realities of the public sector inadvertently inhibit innovation, which is typically not experienced by the private sector. These realities include complex regulatory frameworks, extensive stakeholder buy-in, non-linear political decision making and shortages in funding (Klein, 2015).

\section{Structure of Transit Agencies}

With regards to how innovation can be incorporated into the organizational structure of transit agencies, there are some structural elements that need to be taken into consideration in the composition of a framework. Much like the public sector as a whole, public transit agencies are a bureaucracy. As noted by Burns \& Stalker (1961) bureaucracies are typically mechanistic management systems grounded in hierarchy and stability. To further complicate the management structure, a significant 
amount of the workforce consists of transit operators, staff who are responsible for operating buses and trains to take customers from Point A to B. Transit operators do not regularly see a supervisor and are seldom asked to attend meetings as operators are needed to conduct the core work of driving vehicles to maintain service (Adams, 2015) To promote and communicate the importance of innovation and continuous improvement, close attention must be placed on integrating transit operators as they are a significant mobile workforce for the transit agency.

To provide a reliable and safe transit service daily, transit agencies rely very heavily on hierarchy and structure, which is enforced and informed by standard operating procedures. By having an organizational culture built on long-standing policies, programs and regulatory frameworks foster a set of deep-seated, change-resistant perspectives from many in the transit labor force (Transit Cooperative Research Program, 2003).
The Transit Cooperative Research Program (2000) discusses transit agency organizational dynamics that are essential to be acknowledged and integrated when developing process improvement initiatives. These organizational dynamics include:

\section{Public Character}

The "public character" of transit agencies often slows both market responsiveness as well as changes in organizational roles due to the influence of attention to legal requirements, policy-making procedures and political dynamics

\section{Budget Processes}

Processes involved in the development of annual and short-term budget cycles often drive decision-making. Transit agencies are required to submit detailed operating and capital budget along with corresponding strategies for political approval on an annual basis.

\section{Labor Interests}

Transit labor interests are a strong element in transit governance and unfortunately labor-management relations have tended to be adversarial at times where incremental change is brought through non-innovative approaches such as arbitration, mediation and negotiation processes 
Funding

Consistent problems with funding availability, predictability and reliability require management to focus on marginal improvements to existing services and cost-control.

\section{Performance Measures}

Many front-line staff are not appraised by performance as it common in the public sector, compensation and rewards are based on years of service

\section{Strategic Planning in Transit Agencies}

A clear strategy that promotes and encourages continuous improvement and innovation that is supported by management and all levels of staff is vital for success in fostering the generation of novel ideas, robust employee involvement, and the deployment of process improvements in transit agencies. Strategic planning processes are commonly used by transit agencies to formulate objectives, policies and directions to create a roadmap for the agency for 5, 10, and even up to 25 years. There is an increased recognition that strategic planning is not sufficient to solely ensure success; effective leadership is also required to develop and implement strategic plans (Transit Cooperative Research Program, 2005). Strategic management is required to oversee implementation and ongoing management of strategic plans. There has been a trend to 'open up' the process to involve as many people as possible rather than a 'top-down' approach developed largely by top management and then imposed on an organization.

Calgary Transit, the transit agency for the city of Calgary, Alberta, developed a 30-year operating and capital strategic plan, Route Ahead, using a robust staff and public engagement initiative that used extensive idea generation to inform policies and strategies. Strategic management is utilized in RouteAhead where new plans, policies and programs are aligned to the plan's key principles for transit (City of Calgary, 2016). To gauge the success of strategic plans, there must be a link to other important business processes such as budgeting and performance measurement (Transit Cooperative Research Program, 2000). Innovation must be integrated into strategic planning for an organization, but it also needs to diffused throughout the organization, becoming one of its foundational principles (Deloitte, 2011).

A key study on the use of strategic planning in the public transit environment involved a survey of 104 transit systems in the United States. It concluded that agencies conducted strategic planning processes to develop long range service and capital plans for budget submissions. There were very 
limited attempts by transit agencies to use strategic planning to conduct idea generation on strategy for continuous improvement strategies (Transit Cooperative Research Program, 2015).

\section{Innovation Processes in Organizations}

A clear strategy that encourages and support innovation and continuous improvement supported by management and staff at all levels is critical to foster an innovative culture in organizations. Dougherty and Hardy (1996) note that the lack of a strategy that specifies innovation in an organization may result in a failure of innovation efforts. The development of a clear strategy and process for advancing creative ideas including creative problem solving and collaboration is vital for innovation to live and survive in an organization (Doughery \& Hardy, 1996; Keene \& Singh, 2015). Organizations that are intent on building a shared vision should encourage staff to develop their own personal visions. If staff do not have a personal vision, then they sign up for someone else's vision, creating an environment of compliance not commitment (Senge, 1990). Christensen (2011) identifies process as "the patterns of interaction, coordination and decision making" where employees utilize and transform resources into different products and services. Having a place and process for staff ideas to land and be evaluated has been referred to as an "innovation pipeline" (Nagji \& Tuff, 2012; Keene \& Singh, 2015) where companies have been able to see benefits such as the elimination of siloed organizational structures and developing more lateral and vertical relationships and collaborations across organizations internally and externally.

Organizations that do not have structures and processes that encourage and support innovation, build capacity among staff, or share best practices experience a slow uptake to innovation (Thenint, 2010; Keene \& Singh, 2015). As an initial step to the creation of a continuous improvement program at the Regional Transportation District (RTD) in Denver, Colorado, staff completed a comprehensive study to identify best practices in innovation within the agency informed by staff engagement to begin to the layout a continuous improvement framework, process and strategy that is presently being deployed across the transit agency (Regional Transportation District, 2015a).

Having clearly defined corporate objectives that foster innovation and accompanying processes for idea generation and evaluation is necessary to measure and assess success (Klein, 2015). Defined objectives and metrics to measure effectiveness created collaboratively with staff allowed management to focus more time on working 
with the staff team to meet milestones as opposed to harping on them about day-to-day issues. Having a strong structural backbone frees staff to take risks. Intentionally testing ideas in a goal-oriented institutional framework assists in creating accountability through tracking progress (Klein, 2015).

\section{Fostering a Culture of Innovation with Employees}

How organizations harness the brilliance, knowledge and desire of employees to work smarter as well as foster champions is key in promoting innovation in organizations. Organizational culture of public sector agencies can create conditions where top managers are disconnected from the front lines. This creates a barrier through difficulty in establishing a shared understanding with front line staff on issues and possible solutions (Singh, 2013). Bason (2010) highlights three key benefits to employee driven innovation within organizations. Firstly, employees in front-line positions often hold detailed institutional knowledge and detailed experience about processes, tasks and end-users that they work with. Front-line expertise is essential to include in organizational innovation processes (Bason, 2010). Secondly, involving employees in an organization's idea generation process creates ownership. Furthermore, job satisfaction is an innovation engine whereby positive relations and creativity drive innovation. This creates an environment wherein staff feel respected, trusted, listened to, and taken seriously. To reap these benefits of employee driven innovation, top management must take responsibility for championing and enabling innovation as a bottom-up process and move away from the traditional topdown government approach to idea generation and strategy (Bason, 2010).

Organizations need to embrace team learning, which is the process for developing and aligning the capacity of a team to create results its members truly desire (Senge, 1990). Teams must learn how to tap the potential of many minds, create "operational trust" where each team member is conscious of the actions of other team members and the understanding that the actions of senior teams are actually carried out through other teams throughout organizations (Senge, 1990). There is additional wide ranging literature on soft systems thinking, organizational learning and transformative design which deal with complexities of learning through change as discussed by Senge, 1990 and Wheatly, 1992 and many others.

Fernandez and Rainey (2006) identify the structural organizational support that is required to foster employee driven innovation. Top management support and commitment to innovation and continuous improvement is 
crucial (Fernandez et al., 2006). In the organization 'idea champions' need to be identified to lead the innovation transformation. Identified staff who are 'idea champions' are highly respected individuals in the organization who maintain momentum and commitment to change. A guiding coalition of "idea champions' needs to be able to marshal resources and emotional support with legitimacy to encourage organizational shifts towards innovation (Fernandez et al., 2006). The absence of champions can lead to a culture of low risk tolerance (Thenint, 2010; Keene \& Singh, 2015).

Widespread participation in change processes is a primary approach to overcoming resistance to change. It is vital for management to encourage widespread employee participation through all phases of a change process, commit time and resources to engagement and participation in change process and to manage it properly (Fernandez et al., 2006)

\section{Resource Application}

The ability to access and deploy resources is integral in ensuring the success of innovation and continuous improvement programs and initiatives in organizations. Innovative ideas require resources and the public sector has a scarcity of resources in terms of staffing and budgets to dedicate to non-core operational activities (Singh, 2013). Resources may include but are not limited to time, equipment, funding, technology, information and relationships (Christensen, 2011; Keene \& Singh, 2015). The ability of an organization to scale up and "right-size" levels of support and resources is a key indicator of its ability to position itself as a leader in innovation. Resources are needed and distributed throughout the organization to support innovation (Dougherty \& Hardy, 1996; Keene \& Singh, 2015). Organizational changes associated to a movement towards an innovation-oriented environment could require a redeployment and/or redirection of scarce resources to support new activities including developing a plan or strategy for implementing change, communicating the need for change, training employees, developing new processes and practices, restructuring and reorganizing the organization, and testing and experimenting with innovations (Fernandez et al., 2006). 


\subsection{Methodology and Methods}

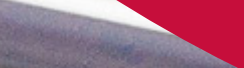




\section{Methodology and Methods}

This study is based primarily on a multimethodology approach utilizing case studies, literature review, staff interviews and a policy and strategy review. A multimethodolgy approach was used to mix qualitative and quantitative methods to analyze and document findings using multiple data, methods, and perspectives (Brewer \& Hunter, 2006). Case studies have been documented on the best practices and processes for internal continuous improvement and innovation of four transit agencies comparable in size and organizational structure to TriMet. A review of internal policies and structures at TriMet as they relate to continuous improvement has been undertaken to understand existing structures that are currently in place to build on for an innovation framework. Interviews of TriMet staff from eleven different sections with staff ranging from Bus Operators to the General Manager were conducted to obtain factual information and professional opinion on a range of considerations from idea generation processes to engagement that would inform a future innovation and continuous improvement framework for the agency.

\section{Literature Review}

A multi-disciplinary approach has been used for the literature review with research from the fields of strategic planning, change management, corporate culture transformation in the public sector and organizational behavior has been consulted. Special attention has been paid to literature on organizational structures and cultures of transit agencies. The literature informed key elements that are required to develop a continuous improvement and innovation framework in transit agencies and are discussed in detail in section 3.0. Benefits of undertaking a literature review for the purposes of a research study involve demonstrating a familiarity with a body of knowledge to establish credibility with a topic, showing a path of prior research and linking it to the current project, integrating what is known in the subject area and stimulating new ideas (Neuman, 2007).

\section{Case studies}

Case studies focused on evolving successful continuous improvement processes and innovation frameworks from transit agencies similar in size (in terms of staff), organizational structure 
(number of divisions, operating locations) as well as agencies identified by TriMet staff as transit systems of interest for existing continuous improvement and innovation processes. Case studies assisted in the identification of approaches to integrate continuous improvement processes in comparable transit agencies and assisted with identifying best practices that could be integrated in a future continuous improvement framework for TriMet. Analysis of continuous improvement and innovation initiatives has been augmented by telephone interviews with transit agencies staff from Denver, Los Angeles, Salt Lake City and Seattle to provide insight on the development and outcomes of their respective continuous improvement programs.

\section{Review of existing plans, policies and programs}

A review was undertaken to gather and analyze existing and former plans, policies and strategies as they relate to continuous improvement and innovation at TriMet. Key analysis was summarized on how existing plans, policies and programs can be integrated into a future continuous improvement framework. TriMet staff has provided information ranging from corporate strategic goals, budget plans, organizational structure, employee engagement survey, capital project sustainability report and program information on the former agency productivity improvement process.

\section{Employee Interviews}

Semi-structured interviews were held with TriMet staff from a range of positions traversing the organizational hierarchy over a three-day period in July 2016 in Portland, Oregon. The semi-structured interview was utilized to allow for flexibility to move back and forth between different items discussed in the interview and to be receptive to information that may not be identified in the initial planning stages of structuring the interview (Adams, 2015). A total of 19 employee group semi-structured interviews were conducted structured by working group. Invitations to participate in the semi-structured were sent by email with responses and scheduling coordinated through staff in TriMet's policy and planning section. Confirmed staff were provided the consent form and interview questions in advance of the semi-structured interview. The consent form was reviewed at the beginning of the interview. Interviews were held at Harrison Square (TriMet Administrative Head Office) and the Center Street Operations Headquarters (one of TriMet's operating centers located in SE Portland). Interviews were 60 minutes in length. 
Below is a listing of the sections that were interviewed for this study:

Capital Projects

Executive Directors Team

Finance and Administration

General Manager's Office

Information Technology

Maintenance (Bus and Light Rail)

Public Affairs (Communications and

Marketing, Customer Information,

Location Based Services, Policy and

Planning)

Safety and Security

Transportation (Bus Operators, Operations Planning)

The primary purpose of the semi-structured staff interviews was to understand the existing idea generation processes, communication, engagement and decision making structures that would inform a future innovation and continuous improvement framework for the agency. Two sets of interview questions were developed with one set for staff in professional roles (e.g., purchasing, communications, planning and policy) speaking to process and programs related to idea generation and to understand how decisions are made in the agency. A similar set of interview questions was created for front line staff (e.g., bus operators, customer service agents) that focused on how information is communicated to front line staff in the agency and how front line staff participate in engagement programs. Interview questions for the professional staff and front line staff are provided in Appendix C.

\section{Project Strengths and Limitations}

In person semi-structured staff interviews were conducted over the course of three business days, which provided a time constraint in engaging staff in this study. There was a great effort placed to get a diversity of staff from varying positions and authority within each identified division to obtain perspectives on continuous improvement and innovation within TriMet. Sixty staff participated and contributed in semi-structured interviews and has provided information on past and current corporate initiatives and policies. There are approximately 2,700 staff at TriMet, where the perspectives of the sixty staff provide a snapshot of professional opinion and guidance on what elements are needed for a future continuous improvement and innovation framework for the agency. Comparative case studies are widely used for academic literature and studies although the limitation of this approach is that it is critiqued as assumptive and has the opportunity to overgeneralize the political and cultural context within each case (Booth, 2011). 

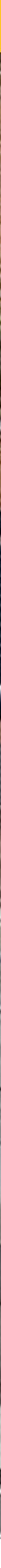


\section{Case Studies}

Case studies were developed for this report to gather insights on best practices and lessons learned from comparable transit agencies that have developed and implemented continuous improvement and innovation programs. Staff at TriMet and the American Public Transportation Association informed the selection of transit agencies that have been documented as case studies. Telephone interviews of key staff involved in continuous improvement and innovation programs from King County Metro in Seattle, Washington, Regional Transportation District in Denver, Colorado (RTD), Los Angeles County Metropolitan Transportation Authority (LA Metro) and the Utah Transit Authority (UTA) in Salt Lake City, Utah are discussed and documented in this section. The concept of continuous improvement and innovation in their respective agencies is a new concept wherein most programs and initiatives have only existed for the past 2-3 years.

\section{(11) Metro}

\section{Los Angeles County Metropolitan Transportation Authority (LA Metro)}

\section{Context}

Under the leadership of LA Metro's new CEO Philip Washington, LA Metro launched the Office of Extraordinary Innovation (OEI) in the fall of 2015. This office is designed to seek and implement innovative transportation solutions that involve financing, public-private partnerships, project delivery, joint development, security, technology and operation. The team consists of 7.5 FTE's composed of a Chief Innovation Officer, Deputy Chief Innovation Officer, Innovation Manager, two Metro Fellows (members of a staff development program rotation), one academic fellow and administrative support. This new office is tasked with the development of the agency's strategic plan, which will outline the agency's overarching vision for transportation and establish a performance management plan for the transit agency. Efforts for innovation and continuous improvement are presently focused on the solicitation of ideas from the business community and community partners. Internal efforts on continuous improvement and innovation 
will be a key focus in the development of the agency's performance management plan as a component of the new strategic plan.

\section{Approach}

Key objectives for OEI are to create an environment of openness, innovation and experimentation within LA Metro. OEl has commenced work to introduce pilot programs that can demonstrate the potential to achieve goals through experimentation and innovation. One process similar to TriMet that LA Metro utilizes as a conduit and portal to obtain and evaluate innovative ideas is to leverage the agency's existing unsolicited proposal process. This process is seen as an open door policy for innovation and new ideas. Proposals are independently developed with the proponent without Metro's supervision and direct involvement. The proposal must sufficiently detail that its benefits supports LA Metro's vision and responsibility of delivering reliable and efficient transportation options to the residents of LA County. To date, the OEl has received 25 unsolicited proposals with 13 proposals being rejected, 6 proposals advancing to the second phase of analysis and the awarding of two contracts. A simplified diagram of LA Metro's evaluation of unsolicited proposal evaluation process is depicted in Figure 2.

\section{Insights}

In terms of pilot projects, OEI documented two pilot projects that are presently being evaluated, one post-implementation and the other pre-development. To enhance connectivity to the recently opened Expo Light Rail Line extension to Santa Monica, LA Metro partnered with uberPOOL to provide an additional "last mile" transportation option between Expo Line stations and the end destination for the transit customer. This 2-week

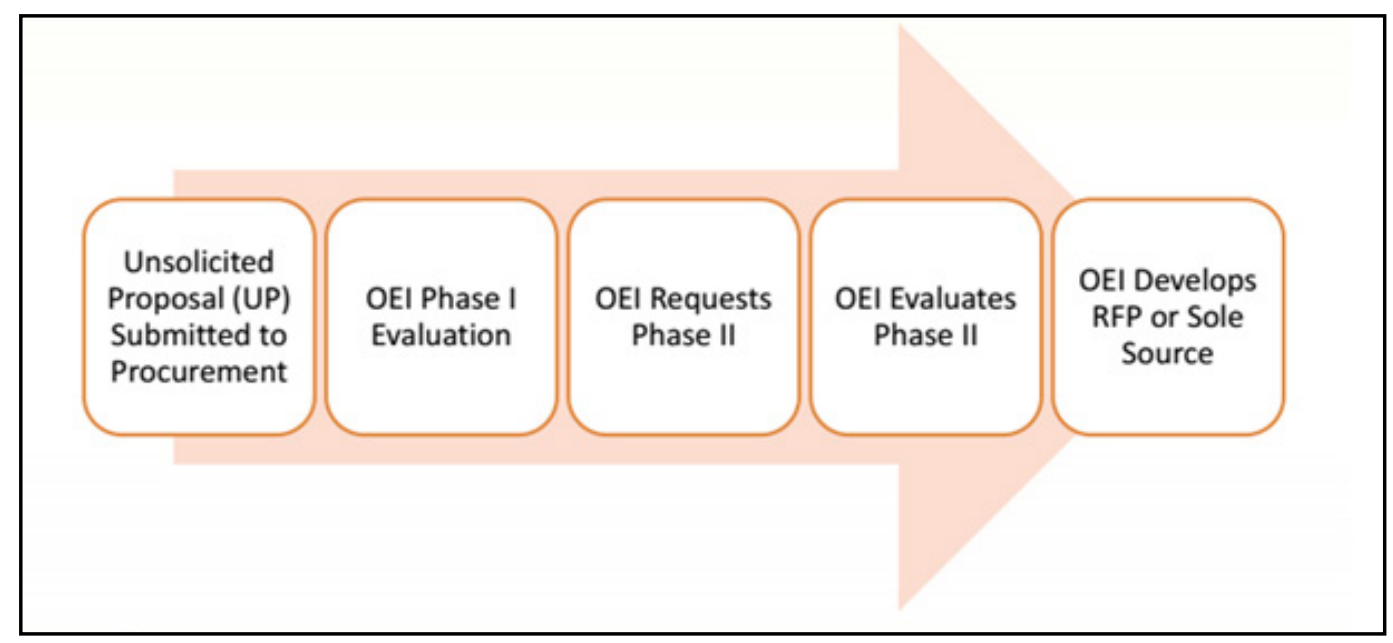

Figure 2: LA Metro's Unsolicited Proposal Evaluation Process (Source: Los Angeles Metro, 2016). 
pilot project was the first time LA Metro partnered with uberPOOL. Key elements of the partnership included the placement of ads on light rail vehicles and stations for users to download uberPOOL, placement of designated pick-up and drop-off locations with associated directional signage for uberPOOL vehicles at Expo line stations and briefing LA Metro communications staff that uberPOOL is a transportation option that the transit agency is supporting.

To implement this partnership, staff worked extensively six weeks in advance of the station opening to finalize contract details, build support with internal staff to permit and allow uberPOOL to participate in a partnership with LA Metro and address issues of concern from Uber specifically with confidentially. OEI staff is presently evaluating the success of the pilot to determine future partnerships similar in scope for "last mile connectivity". One statistic that has been reported as a part of this initiative is that there were 10,000 downloads of the uberPOOL app associated with the partnership. A second pilot project under consideration for implementation is the development of a general interest transit podcast to share stories of about transportation and mobility in LA County. One of the goals of this podcast is to help create a sense of a transit culture within the region, which can be exemplified when considering cities like New York City wherein citizens have embraced transit as a part of their cultural identity. This initiative is being developed in collaboration with a local reporter from the National Public Radio and LA Metro staff in OEI and the agency's communication department. 


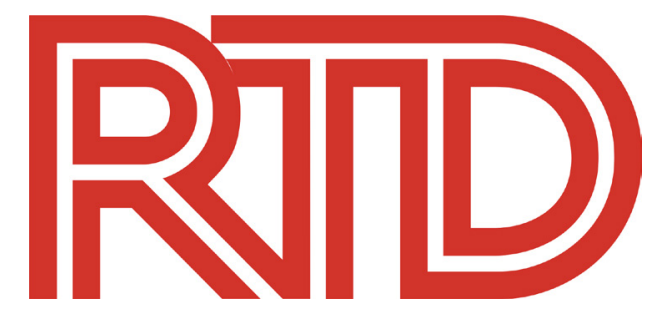

\section{Regional Transportation District (RTD)}

\section{Context}

Located in Denver, Colorado, the RTD launched the Peak Academy, a training and leadership program in continuous improvement and innovation in 2015. The deployment of the Peak Academy program is an initiative to respond and complement the strategic goal to "foster a two-way communication culture with every level of the organization". The focus of the 2015-2020 RTD strategic plan is to transition the organization from operating and building to operating and maintaining with the opening of multiple light rail transit, bus rapid transit and commuter rail projects in the region (Regional Transportation District, 2015b). To inform strategies in the strategic plan, an employee engagement survey was completed. Key findings from the survey included that employees felt disconnected and left out of the decision making processes within the organization. The survey also suggested that improvements in overall employee communications are needed, especially with the mobile nature of the workforce among employees working remotely such as operators and other personnel deployed in the field.

\section{Approach}

Staff from RTD's Long Range planning division conducted interviews of agency staff and documented every program and process in the creation of the agency's Best Practices Report. This knowledge sharing report documented and discussed best practices in the realm of partnerships, processes, workforce, internal communication and technology. Examples of initiatives, programs and processes identified by section at RTD in the Best Practices Report that are related to fostering continuous improvement and innovation include:

Unsolicited Proposal Policy to encourage public sector innovation to benefit RTD projects

Multi-Agency Exchange (MAX) Program to share knowledge and strengthen contacts between RTD and peer agencies (Regional Transportation District, 2015a)

In the creation of a continuous improvement program for RTD staff to enhance two-way communication and foster employee engagement, RTD leveraged the resources of the established Peak Academy program implemented by the City of Denver.

The Peak Program is a continuous improvement program that is a program of the Mayor's Office. 
Key values of the Peak Academy are:

- $\quad$ Achieving measurement results through continuous improvement

- Make the city of Denver the most well-run city in the nation

- Patience with people and impatience with processes

- Failure leads to breakthrough

(City of Denver, 2016a)

The Peak Academy's framework focuses identifying tools to identify waste, utilization of the A3 planning tool as depicted in Figure 3 that walks staff through the continuous improvement process and tools to eliminate waste (City of Denver, 2016b). The A3 planning tool walks staff through a nine-step process of issue identification, exploration of ideas, implementation strategies and reporting of results.

Internal RTD staff provides additional support with assisting with process mapping, facilitating continuous improvement and providing guidance on solutions to identify and eliminate

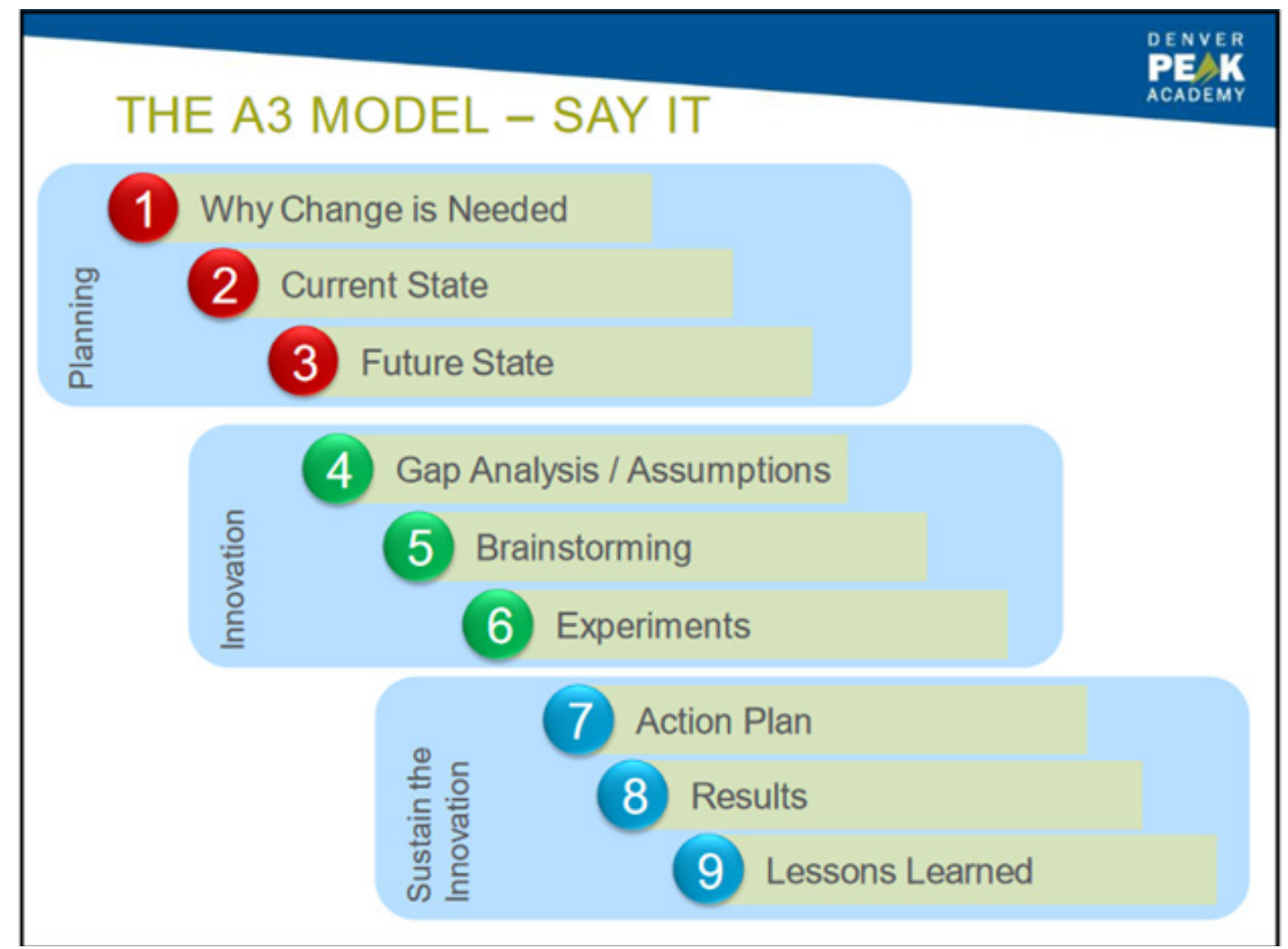

Figure 3: The RTD A3 Planning Model for Continuous Improvement 
waste. Within the first year of the Peak Academy within RTD, 250 staff members received initial training on the program. Change agents were identified in key areas in RTD such as Bus Maintenance and were provided a weeklong training on continuous improvement approaches from the Peak Academy. Staff deploying the Peak Academy at RTD undertake in-the-field check-ins with change agents who have received Peak Academy training for additional organizational support and follow up to keep momentum in the program.

Insights

Continuous improvement initiatives are widely communicated to RTD staff. Staff members who develop and implement initiatives utilizing training from the Peak Academy are showcased in the "Brightspot" section of the weekly internal employee newsletter the Monday Morning "O".
Continuous improvement initiatives that have been communicated through "Brightspot" include:

Streamlining of bus mechanic recruitment through optimizing interview and testing times for applicants

Improving exterior signage on buses to identify proper servicing practices for maintenance staff.

At the end of the "Brightspot" story, there is a call to for action to contact the Peak Academy team if the staff member wants to receive continuous improvement training. The full text of a "Brightspot" continuous improvement story is provided in Appendix D. 


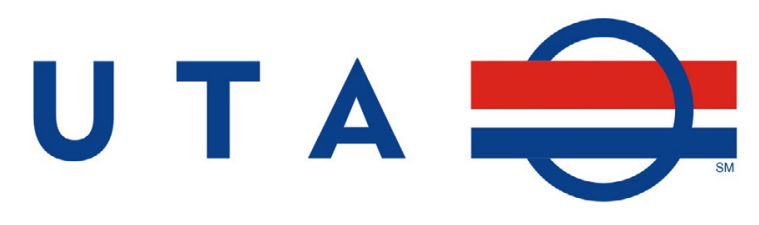

Utah Transit Authority (UTA)

Context

The origins of continuous improvement at UTA come from the ISO 9001 certification for quality management and ISO 14001 certification for environmental management (Utah Transit Authority, 2015). During the ISO certification process in 2006, UTA staff documented internal business and operations processes. In 2012, staff commenced a continuous improvement program focused on the Shingo Model. Five elements comprise the Shingo Model (systems, tools, results, guiding principles and culture) and it is recognized that each of these elements interact and impact one another. Ten staff members were selected from across the agency to participate in UTA's initial continuous improvement team to refine and deploy an agency-wide continuous improvement program.

\section{Approach \\ Through analysis of the agency's needs paired with existing continuous im- provement methodologies such as Lean and the Shingo Model, staff developed "The UTA way", an agency tailored approach to continuous improvement.}

It was seen by staff that for continuous improvement to become a part of everyday business in the agency, a common language is vital. The UTA way identifies the role of each individual staff member regardless of position in the agency of how they can orient their work to embrace continuous improvement and innovation every day. The integration of continuous improvement and innovation focuses on questions of what, who, why and how. Figure 4 documents the UTA Way.

Extensive training curriculum materials have been developed for the "UTA Way" and are presently being deployed across the agency. All staff (professional and front line staff) attend required training on the UTA Way. A training session on continuous improvement is offered as an operational module style training course for UTA staff, and nearly all leadership staff have attended this training. All staff are required to complete the "Voice of the Customer, Business and Process" course framed by the UTA Way.

Specifics on the three voices are provided below:

Voice of the customer: the needs, wants, expectations, preferences, both spoken and unspoken, of business' customers whether internal or external 


\section{Living The UTA WAY}

Good people creating a good transportation value for a better quality of life.

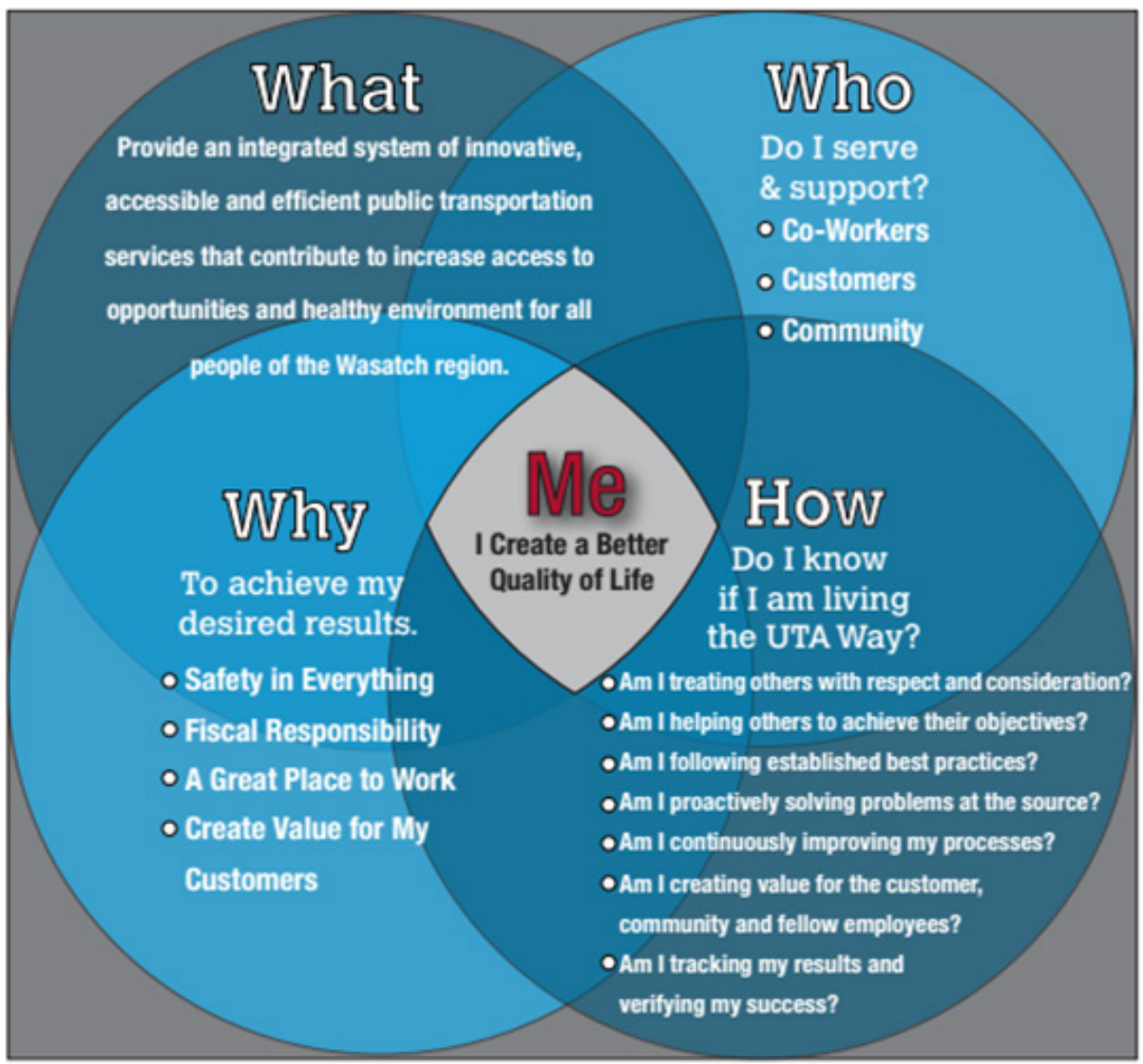

Figure 4: The UTA Way

Voice of the business: encompasses the primary needs of a business and its stakeholders, including sustainability, revenue, growth and market share, and can be used to establish goals and define success

Voice of the Process: the performance and capacity of a process to perform in relation to both customer and business needs. This is usually expressed as an efficiency or effectiveness metric (Utah Transit Authority, 2016c)

The UTA Way is knitted into the three voices showing application and results of listening to all three voices of the organization. Out of the four transit agencies contacted, UTA is the only transit agency that provides mandatory continuous improvement and innovation 
training to all employees. Transit operators receive the training as a one-hour participatory lecture during the annual refresher process.

\section{Insights}

Presently, the UTA continuous improvement team consists of five staff members who provide support functions to staff undertaking continuous improvement initiatives across the agency. The ultimate goal of the continuous improvement team is to transition away from solely one corporate team to embedded staff in each working division. Pilot projects originating with support and training from the continuous improvement team have included developing new ways to troubleshoot buses breaking down on the road through the regeneration process and better scheduling preventive maintenance for buses with new the emissions control engines. Staff have also optimized the transit operator bidding process through having real time information on schedule signups from multiple operating divisions. UTA has leveraged a partnership with the Centre for Innovative Culture at Westminster College. Through this academic partnership, UTA staff participates in roundtable discussions, field visits and workshops about continuous improvement with businesses in the manufacturing sector to share best practices and advice. 


\section{King County METRO}

\section{King County Metro}

\section{Context}

A culture of continuous improvement developed in King County Metro has been achieved through the corporate wide deployment of LEAN throughout King County, championed by the King County Executive.

The foundation of LEAN is continuous improvement and respect for people where attributes of a LEAN culture include (King County, 2016):

All work is aligned towards a shared purpose

People are valued as developed as problem-solvers

Visual systems make work transparent

Problems and abnormalities are made visible

Decisions are based on facts and data

Everyone embraces scientific data

Failures are treated as learning opportunities
A core team of 10 King County staff members was assigned to lead the LEAN transformation across the entire municipal government including King County Metro. Dedicated staff from King County deployed rapid improvement events, which entailed process review and problem solving on a selected process issue during a one-week intensive engagement event.

Approach

The initial implementation of LEAN initiatives through the centralized county-wide LEAN staff team and rapid improvement events had limited success. An early win was found in the vehicle maintenance division through a review of on-hand bus part inventory process where inventory was reduced by 30 percent and costs were reduced by 2 percent. With the centralized approach there was little follow up and support for LEAN initiatives. King County Metro identified the need to create a LEAN program specifically for the transit agency to foster a culture of continuous improvement. The Kaizen Promotion Office, kaizen being a Japanese term for "improvement" was formed within King County Metro composed of six staff members. Four members are on full assignment to the office and two staff positions are offered as a rotation for King County Metro staff to develop as LEAN experts who are then embedded within operating divisions in the transit agency to lead and support LEAN initiatives. 
Insights

To foster and incubate a culture of continuous improvement within King County Metro, effort was placed into collaborating with staff in middle management positions as they are at an organizational level that has a firm understanding of the needs of frontline service delivery and management accountabilities. Processes have been transformed in the agency's vehicle maintenance division through LEAN.

Visual management systems have been deployed where clear key performance indicators have been identified are discussed with all staff in regular shift meetings. Discussions in shift meetings with the visual management system focus on the causes behind the numbers and what counter measures can be put in place to address identified negative trends. Vehicle maintenance has seized the opportunity to deploy the LEAN approach with inventory management, repairs and preventive maintenance on a newly delivered fleet of New Flyer buses at the Ryerson Base in Central Seattle. LEAN-inspired processes used on the new bus fleet at Ryerson will be evaluated against existing processes regarding inventory and maintenance at other operating divisions across the transit agency.
King County Metro staff leverage existing partnerships and training opportunities with LEAN with other continuous improvement leaders in the Puget Sound region. Partnerships exist between the transit agency and Seattle Children's Hospital and the state of Washington. Staff participates in LEAN fieldtrips to companies and organizations in the health care and technology sectors that have embraced LEAN. To facilitate shared learning and celebrate success, the state of Washington organizes and hosts an annual state-wide conference on LEAN. 


\subsection{Employee Interview Findings}




\section{Employee Interview Findings}

This section provides a summary of the findings of the 19 interviews conducted with TriMet employees from across the transit agency in July 2016. The primary purpose of the semi-structured staff interviews was to understand the existing idea generation processes, communication, engagement and decision-making structures that would inform a future innovation and continuous improvement framework for the agency. Two sets of interview questions were developed with one set for staff in professional roles (e.g. purchasing, communications, planning and policy) and a complementary set of interview questions were created for front-line staff (e.g. bus operators, customer service agents). Interview questions for the professional staff and front line-staff are provided in Appendix C. Themes from the interviews are organized by key considerations from staff.

\section{There is firm desire to bring forward ideas from the front line}

Staff identified that there is not a centralized portal and corresponding evaluation process for idea generation at TriMet. It was agreed upon that there is a significant "brilliance" of organizational knowledge within front-line staff. There is a desire of front-line staff to engage in improvement processes through providing expertise, guidance and "horsepower". A structured opportunity for management to listen needs to be in place to harness the expertise of front-line staff.

\section{Language that fosters the status quo needs to be discouraged by management}

Staff commented that many ideas die and are not developed within the organization due to common responses that amplify status quo approaches to problem-solving and operational service delivery. It is common to hear statements such as "this is not the way we do things here" and "this is what we have, make it work". Status quo statements and philosophies inhibit the encouragement of continuous improvement and innovation. Management needs to actively discourage this mentality and vocabulary among staff in the organization. 


\section{TriMet is evolving as an organization}

Staff commented extensively that TriMet is at a turning point in its organizational history. For many years, the organization has been oriented to extensive service expansion with the opening of numerous expansions to the MAX light rail system and responding to the fluidity of TriMet's financial realities. The organization is starting to turn its focus to operations and maintaining new assets. This is an excellent time to commence discussions and strategies on continuous improvement and innovation that enhances operational productivity.

\section{Improve internal partnerships between divisions}

Staff identified a strong desire to increase opportunities to improve internal partnerships between staff. Successes of the "Inside Customer Service" training from the agency's customer information staff for operations staff was highlighted as a successful example of creating a shared information partnership of the roles and expertise of two divisions. Staff identified that many divisional silos exist in the organization through the differing roles and accountabilities present in each division and the limited understanding of how decisions made in one division affects other divisions. The silos are also amplified by the reality that divisions are spread out in different locations across the region and scheduling coordination meetings in different operating centers can be challenging. In multiple interviews, staff identified cross-training opportunities as an initiative that would assist staff in understanding different divisions and roles in select divisions that staff regularly work with (e.g., customer information and dispatch). Cross-training would create shared understanding, build relationships and enhance communication between divisions.

\section{It is difficult to reach out to front line staff}

TriMet employs numerous tactics to communicate information on service and corporate initiatives for bus and rail operators. Forms of communication include placing information in the onboard bus operator pouch, digital flat screens in the report areas, bulletin boards and emails to TriMet employee email accounts. Many bus and rail operators complete a shift without coming to a bus or rail garage. Operators are receiving information through word of mouth from other operators and the union website as unofficial sources to get news and information on agency initiatives. Efforts are needed to better understand on how to engage bus and rail operators to optimize 
ways to convey information on agency initiatives, especially to join Continuous Improvement Teams. In-class training time as a part of the annual training refresher was identified as an excellent opportunity to engage staff in mobile positions such as bus and rail operators advice and guidance on continuous improvement and innovation as it relates to the front line.

\section{Existing processes have elements of continuous improvement and innovation that can be built on}

Three existing organizational processes were identified by staff as ways to engage discussion and initiatives on continuous improvement. Staff cautioned that existing processes are not widely communicated as ways to solicit feedback for continuous improvement, nor that is the initial purpose of the referenced processes. In the absence of a formalized continuous improvement and innovation process, staff are utilizing existing processes to varying degrees to put forward ideas. Three such existing processes are identified below:

\section{Request for Safety Assessment}

The Safety and Security Division intakes requests from all TriMet staff on safety matters and issues identified throughout the transit system and in facilities through the Request for Safety Assessment (RSA) process. Safety and Security staff document each RSA into a centralized database, tracked and assigned to the appropriate division for investigation and response. Findings of the RSA in terms of response and action when required are reported to the originator of the RSA, closing the feedback loop. Staff in many divisions identified high satisfaction with the RSA process of reporting, investigation and responding to requests from TriMet staff. It was commented that staff have also been submitting requests that could be viewed as ideas for improvement framed with safety in mind. One example would be the request for additional lighting at Beaverton Transit Center, a safety, facility and customer improvement at this specific site. Staff commented that the RSA process is significantly better than the previous yellow card safety reporting system used by staff. Concerns with the yellow card process included that yellow cards being regularly misplaced and results of investigations not always reported to staff to close the feedback loop.

\section{Transit Change Review Committee}

Multiple divisions participate in the Transit Change Review Committee, a multidisciplinary working group that reviews and approves changes in 
standard operating procedures and changes to processes within the bus and light rail vehicle fleet. This committee is led by the Safety and Security Division with membership consisting of senior staff from various divisions such as Maintenance, Capital Projects and Operations. Decisions are made through voting and the committee meets on a regular basis (i.e., at least once a month). Initiatives that have involved pilot projects have sought and obtained approval through this committee. The existing structure of the committee could be explored in terms of the participating divisions and decision-making when structuring a future continuous improvement and innovation framework for the agency.

\section{Continuous Improvement Teams:}

TriMet has formed continuous improvement teams consisting of assigned and volunteer staff on specific issues. These teams undertake an analysis of the identified problem and create solutions informed by employee engagement. Presently, Continuous Improvement Teams have been formed for operator washrooms, assaults on bus operators and service reliability. Staff in multiple interviews identified the continuous improvement team that was formed on the reconfiguration of the operator's cockpit on the new Gillig low-floor bus fleet as a great success. Since 2012, TriMet has received 326 new Gillig low-floor buses representing half of the agency's bus fleet. Maintenance staff directly engaged front-line staff, particularly bus operators, to work collaboratively with the vehicle designer to make design and ergonomic improvements to the bus operator cockpit for increased safety and comfort. The collaborative working relationship with front-line staff on the vehicle redesign has been widely recognized in the agency as a success to replicate and the process received an award from the state of Oregon for partnerships.

\section{Other Identified Successful Processes}

Service Planning staff practice continuous improvement with the targeted service review of 2 to 3 bus lines per quarter based on performance data and employee feedback. Staff in TriMet's schedules section solicit feedback on route schedules directly from bus operators on the agency's internal website. Responses to bus operator feedback are provided as a thread for all staff to see. The number of bus operator complaints on concerns regarding issues such as running time and schedule adherence has reduced significantly and scheduling staff are not responding to the same scheduling issue multiple times. 
To foster an environment of idea generation and collaboration, one division identifies the implementation of the business practice of not permitting meetings for half of a day per week to allow staff to brainstorm and spend time on initiatives they feel would enhance their ability to move self-initiated projects that could improve TriMet.

\section{There is a desire for the return of the PIP Program}

Multiple staff in multiple divisions who were employed at TriMet during the deployment of the agency's first continuous improvement program have a desire to see a return of the program. A discussion of the discontinued PIP program is provided in section 2.0. Staff noted that there was great alignment to the concept of the stewardship of public dollars and that projects that PIP spurred helped to make things easier and more efficient for staff. Staff identified the need for management to identify a staff member or division to commence the process of bringing back the PIP program.

\section{Sharing Stories of Success}

Staff from across the agency discussed the need for TriMet to share the stories of success of continuous improvement that is occurring in the organization and that there is room for improvement in creating a shared understanding of success and to enhance employee morale. The awareness of ideas that has resulted in improvements in the ability of staff to enhance their ability to deliver service and improve ways to work more efficiently in the agency is not communicated well internally. Staff commented that greater effort is placed on communicating TriMet's successes to the general public with ad campaigns on the system to help build public support for TriMet as a transit provider. It was suggested that internal communications such as a regular report in the General Manager's quarterly town hall can be used to communicate continuous improvement successes as well messages on the display screens in operator report areas.

\section{Timeliness in technology processes is a concern}

Staff in various divisions have identified concerns about the time duration for changes to technology processes in the agency. To request new technology to support business needs, staff are required to scope out resource and cost requirements up to a year and a half before securing financial approval to proceed with a technology purchase or deployment. Decisions to proceed with a technology process and/or deployment require various levels of approval. Staff noted that because of the lengthy approval and 
implementation time of the requested technology, it could already be out of date upon implementation. The timeliness in conducting a technology process improvement to communicate real time service disruption information has been identified as an urgent need for a review. Presently, to update all communication channels (arrival boards, social media, website and more) takes approximately 20 minutes. Delays in disruption communication erode customer confidence and satisfaction in a transit system's ability to address and remedy service disruptions.

\section{Integrate discussions with front line staff during training}

To deliver on expanded transit service and filling operator vacancies due to attrition, the agency is aiming to hire 20 operators for a training class every two weeks until at least 2018. Staff have identified that this would be ideal timing to instill a culture of continuous improvement on the front-line, particularly among the new pool of bus operators that are joining TriMet through the training process.

\section{Equip management to promote continuous improvement and mandate it}

Staff across the agency commented that management needs to mandate a culture of continuous improvement upon all levels of staff in the agency. To communicate and equip staff to embrace and implement continuous improvement, it was suggested that a training module be developed for management staff on how to foster continuous improvement and innovation in day-to-day work and share best practices and lessons learned on successful continuous improvement and innovation processes used in other transit agencies. Individual performance evaluation should be revised to reflect the importance of management contributions to continuous improvement within TriMet.

\section{Best Practices are being documented and utilized in key capital projects}

The evolution of best practices and lessons learned are being applied successfully on successive light rail transit expansion projects. There has been an increased focus on minimizing impacts, costs and maintenance requirements, especially since the planning and design of the Yellow line, which opened in 2004. Best practices in landscaping, shelter design and groundwater have been successfully implemented on the Green and Orange line 
expansion projects. Lessons learned are well-documented at the close out of each project and updates are made to the Business Procedures Manual in the Capital Projects Division.

\section{The strength of community partnerships differs by Division}

The success and structure of community partnerships varies by division. The Capital Projects division has a strong history of partnering with local artists, small businesses and minority contractors during the design and building stages of various light rail projects. TriMet's Community Affairs program has provided funding to local artists for public art installations at new light rail transit stations. TriMet utilizes a contractor selection model that places the highest score on expertise, not price. Construction contracts are parceled out so that local small businesses and minority contractors can bid and be selected to construct elements of light rail expansion projects. For the recent Orange Line expansion, up to 25 percent of construction contracts were awarded to local small businesses and minority contractors.

Other divisions regularly pursue community partnership for more small, nimble and short-term initiatives. Staff has commented that there are internal hurdles applied to community partnerships, such as insurance requirements and legal agreements. There is no formal community partnership program for short-term initiatives such as partnering with special events or securing multi-lingual facilitation services. Partnerships are being undertaken in an ad hoc fashion where staff is navigating organizational challenges individually. 


\subsection{Recommendations}

$2+x+4$

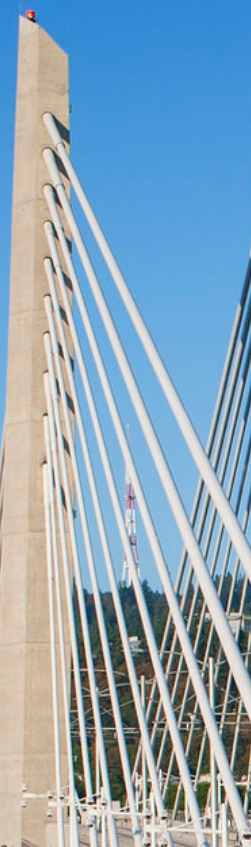

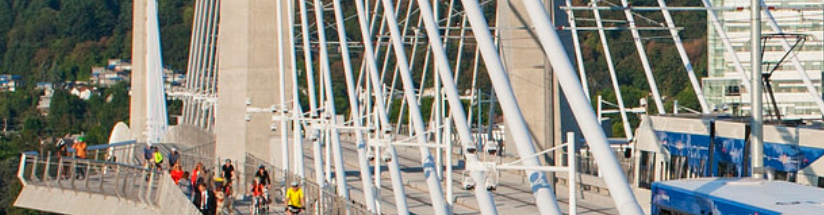
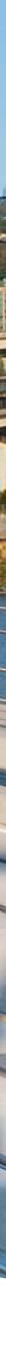

$-$

Twelve recommendations are drawn from the results in the literature review, case studies of comparable transit agencies and employee interviews. The selection of recommendations will evolve based on strategic direction provided by management, opportunities and organizational limitations based on existing priorities and processes. 


\section{Recommendations}

This report is intended to provide a high-level investigation and analysis on ways that TriMet can progress with a continuous improvement and innovation orientation. The following recommendations are drawn from the results in the literature review, case studies and employee interviews. The selection of recommendations will evolve based on strategic direction provided by management, opportunities and organizational limitations based on existing priorities and processes. Continuous improvement and innovation is a consistent evolution of learning in an agency. Recommendations are listed in a suggested chronological order, although numerous recommendations can be implemented simultaneously to create, support and elevate a culture of innovation.

\section{Recommendation 1}

Integrate continuous improvement and innovation in existing strategies

The immersion of the agency values of continuous improvement and innovation need to be documented and advocated by management to staff from across the agency. Key policy documents in the agency such as the Strategic Goals outlined in TriMet's five-year fiscal plans need to promote continuous improvement and innovation to inform decision-making and give traction to the changing orientation of the agency towards embracing continuous improvement and innovation.

\section{Recommendation 2}

Leverage existing processes in the creation of the continuous improvement and innovation program for Trimet

The bones and structure of a continuous improvement and innovation program exist at TriMet. It is recommended that an agency-wide Continuous Improvement Team be formed with membership from every division with participants in positions spanning all levels of the organizational hierarchy (from Executive Directors to front-line staff) to analyze and report back within six months with recommendations on how existing idea generation, engagement and decision making structures can be immersed into a new continuous improvement framework for the agency. Processes that should be considered include the reporting process for the Request for Safety Assessment and the structures and program design of 
the former Productivity Improvement Process. It is recommended that the Continuous Improvement Team should also report back on the additional considerations:

Recommendations on how to implement a centralized portal an "innovation portal' for idea generation for continuous improvement

Evaluation criteria for submitted ideas for refinement and development

Communications plan to showcase successes, risk-taking and lessons learned through ideas implemented through an 'innovation portal'.

An aggressive timeline is recommended to build momentum and show action towards the development of a formalized continuous improvement and innovation framework at TriMet. Selected and volunteer staff assigned to this review will required mandated work time to collect information, analyze and report on and to proceed with a continuous improvement and innovation framework. TriMet could elect to secure consulting resources in the expertise of change management to support but not lead this effort. It is imperative that the development of a continuous improvement and innovation framework is heavily driven and informed by employees.

\section{Recommendation 3}

Develop an agency Best Practices Report

A best practices report as done by RTD in Denver prior to the launching of a continuous improvement program for their agency documented existing strengths and opportunities related to partnering, processes and workforce development. The documentation of best practices would inform the development of a continuous improvement and innovation framework for TriMet and assist in sharing stories of success of individual and divisional contributions in innovation within the agency. The best practices report should inform the findings of the Continuous Improvement Team tasked with reporting on implementing a continuous improvement framework for the agency.

The discussion of lessons learned from successful processes and initiatives should be documented in this report but also illustrative stories of failure should be included. Mistakes are one of the greatest sources of learning (N. Lister, personal communication, August 17th, 2016). New processes and initiatives can be informed by lessons learned from successful and unsuccessful strategies. 


\section{Recommendation 4}

Share stories of success

TriMet can immediately increase efforts to share employee stories of success in process improvement, engagement, problem solving, partnership development and more. Staff commented that TriMet does an excellent job of sharing its successes with the general public (e.g., ads on buses and trains noting that $45 \%$ of customers travel to work in downtown Portland by transit), but stories of success are not widely communicated internally. Opportunities to increase exposure to internal success stories can be the sharing of success as a regular component of the quarterly agency town halls, highlights on TriNET (the agency's internal website) and information screens in report areas.

\section{Recommendation 5}

Invite other agencies to share lessons learned about their continuous improvement programs

It is recommended that TriMet explore opportunities to invite and host transit agencies who have recently developed and implemented continuous improvement and innovation programs to share best practices and lessons learned. The approach and insights of every agency that has implemented a continuous improvement program varies and TriMet can harvest best practices from different agencies to inform and strengthen the development of a continuous improvement framework at TriMet. Agencies that have recently embarked on the journey of continuous improvement and innovation include the four agencies discussed in this report (LA Metro, King County Metro, Denver RTD and Salt Lake City UTA) as well as Calgary Transit, Toronto Transit Commission and the Washington Metropolitan Area Transit Authority.

Recommendation 6 Develop an agency Strategic Plan

Presently, strategic goals and corresponding initiatives are located in multi-year budget documents aligned to fiscal year budget cycles. There is limited awareness of strategic goals and initiatives with front-line staff. It is recommended that TriMet undertake a Strategic Plan that houses all organization initiatives related to operations, maintenance and growth developed with robust employee engagement. The strategic plan would form the basis of all business activity of the transit agency, inform performance management, process development, business planning and partnerships. Strategic objectives and core strategies informed through employee engagement will support in collective buy-in by having employee fingerprints through the organization's playbook for moving the agency forward. Both Calgary Transit 
and Denver RTD have recently completed strategic plans informed greatly by the employees of the respective agencies.

\section{Recommendation 7}

Integrate continuous improvement training into training programs across the agency

Once a continuous improvement and innovation program and 'innovation portal' is created, it is recommended that all employees receive training on the importance of continuous improvement and innovation and how to utilize resources within the agency to bring an idea forward, develop initiatives, implement improvements and measure results. Training can occur at the time of hire for new staff and through the annual refresher training for bus and rail operators.

\section{Recommendation 8}

Visualize and post TriMet's Key Performance Indicators in the agency's operating centers

To assist in identifying opportunities or idea generation and to prevent ideas searching for a problem, it is recommended that TriMet publish and post key performance indicators from the agency's performance dashboard in report areas and bulletin boards.
To provide clarity in identifying and understanding trends, performance indicators can be visualized in a "traffic light" form where green indicates whether the agency is ahead of target, yellow for at risk or red for below target along with trend arrows showing whether performance is trending up or down. Displaying this information with a future "innovation portal" can assist in having staff formulate targeted ideas that could be measured and assist the agency in improving performance. Employees can be engaged at the initial stage of deployment of an innovation portal' by asking what additional performance measures should be tracked and reported on.

\section{Recommendation 9}

Facilitate enhanced front-line and management discussions

To achieve an improved, shared understanding of roles and responsibilities and to solicit feedback on agency initiatives, drafting an agency strategic plan and/or deploying an innovation portal, it is recommended that a continuous employee engagement program with management and front line staff is developed and implemented. Twice a year Calgary Transit staff and managers host "Transit Talk", a half day engagement session in the bus and rail operator report areas in all four transit garages where front line operators 
and mechanics can speak directly to divisional staff and management to put forward ideas for improvement. All collected ideas and comments from operators and mechanics are inputted, tracked and responded to. A report back on key feedback collected through "Transit Talk" is provided through the weekly employee newsletter and in handouts at the following engagement session.

\section{Recommendation 10}

Make continuous improvement a part of the performance appraisal

Individual performance evaluation should be revised to reflect the importance of management contributions to continuous improvement within TriMet. Participation of individual members of management in continuous improvement initiatives should be considered in pay-for-performance and in an employee's annual appraisal. Continuous improvement should become an ongoing accountability in the day-to-day responsibilities of management staff.

\section{Recommendation 11}

Explore cross-training opportunities

To break down silos and to foster more collaborative relationships across the agency, a formal cross-training or 'shadow-for-a-day' program should be explored for positions and divisions that have a high level of interaction. Creating a shared understanding of how decisions are made in one division affect another can lead to better outcomes in processes and, ultimately, service delivery. An additional benefit is that collaborations can be more easily formed for idea generation between staff who have participated in a 'shadow-for-a-day' program.

Recommendation 12 Formalize the community partnership process

A centralized community partnership process should be explored for TriMet. Community partnership requests channeled through one venue or portal can assist to streamline and remedy ongoing concerns with insurance requirements and legal agreements. A centralized partnership process will allow for the equal evaluation of requests and help to build an understanding of TriMet's strategic objectives externally. A centralized process can also be used as a conduit to encourage idea generation and partnership through the agency's unsolicited proposal process. 


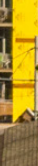
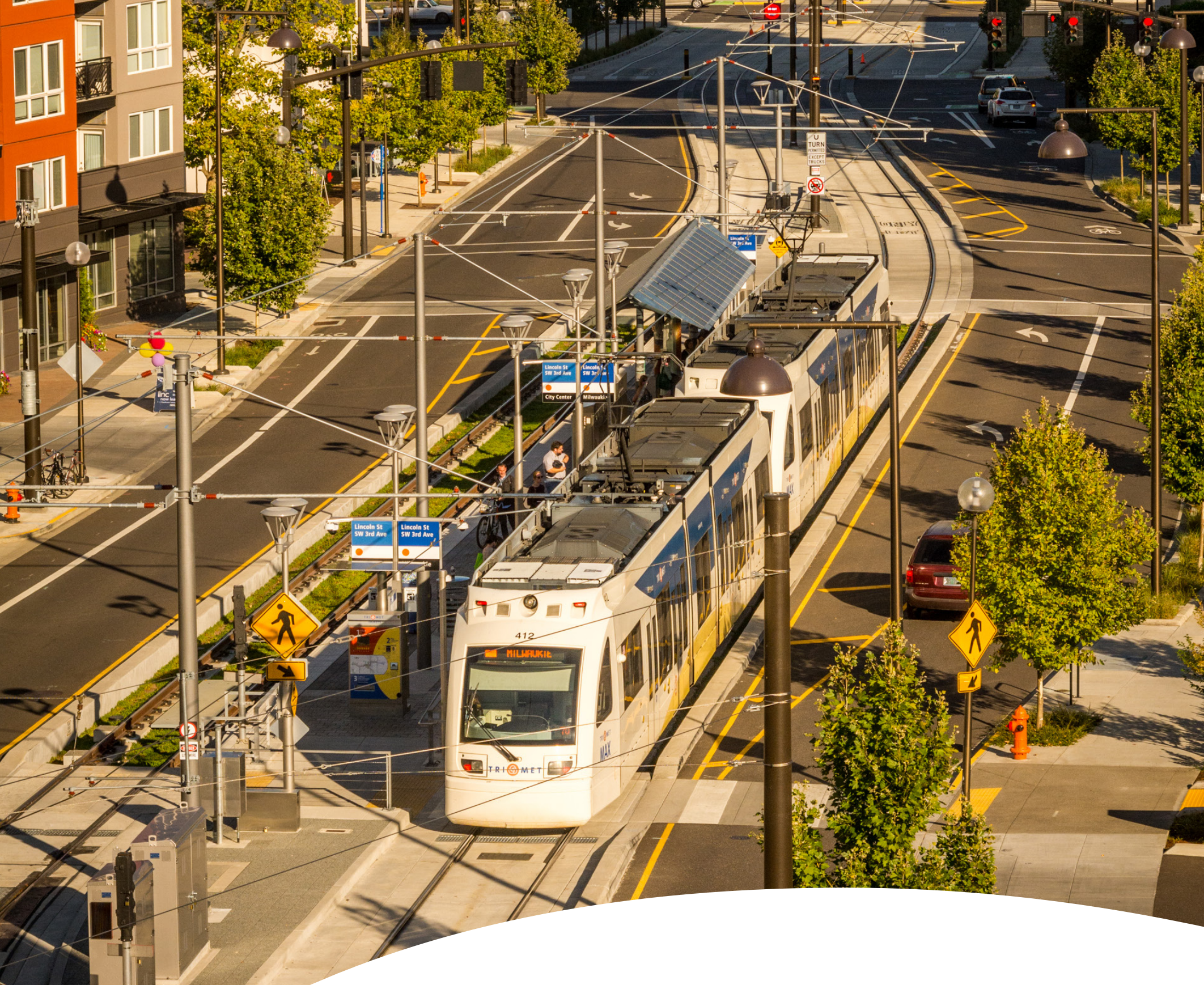

There is no centralized portal for ideas to land and be evaluated and refined through partnerships with staff from across the agency. The structures of continuous improvement and innovation do exist in a few forms at TriMet, such as continuous improvement teams, request for safety assessment process and the transit change review committee. These structures could be integrated into a centralized process for idea generation propelled by employee engagement. 


\section{Conclusion}

TriMet has a lengthy history of innovation within the agency. A number of innovative firsts occurred at TriMet, such as the introduction of the Productivity Improvement Process to empower staff to put forward and implement initiatives that enhances efficiency and reduce costs, utilization of the unsolicited proposal process to develop and implement the first mobile fare payment app in the United States. TriMet was also the first the agency to release real- time information in an open data format for enhanced customer information. There is no centralized portal for ideas to land, be evaluated and refined through partnerships with staff from across the agency. The structures of continuous improvement and innovation exist in a few forms at TriMet, such as continuous improvement teams, request for safety assessment process and the transit change review committee. These structures could be integrated into a centralized process for idea generation propelled by employee engagement. Any new structure created for continuous improvement and innovation should not be linear in its orientation. Opportunities need to exist to share lessons learned of successes and failures to circle back to revisit goals and objectives of a new program and/or structure for continuous improvement and innovation.

TriMet is in transition. Years of significant expansion are now turning to a new reality of an increased focus on maintaining assets and operations. Stories of success of how employees bring forward change that enhances the organization's ability to be responsive and more efficient in this context need to be celebrated and told. There is a thirst for innovation from all levels of staff at TriMet. Now the time to harness the brilliance of each staff member to improve the agency to work better, harder and smarter. 
Appendix A:

TriMet Organizational Structure 


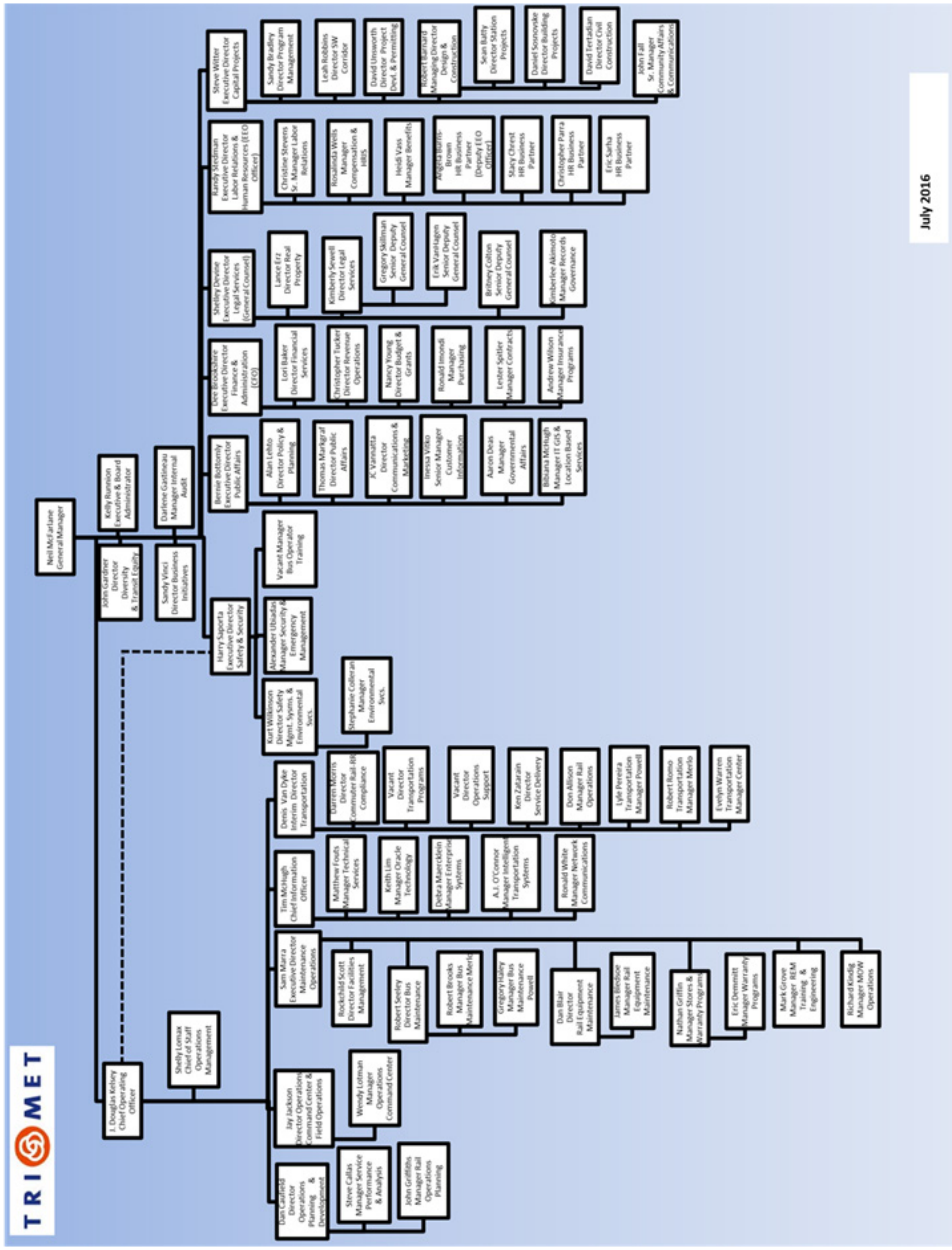


Appendix B:

TriMet Five Year Strategic Goals 


\section{TriMet Five Year Strategic Goals}

\section{TRI (9) MET}

TriMet's Five-Year Action Plan FY2015 - FY2019

Doing our part to make our community the best place to live while embodying the values of safety, equity, fiscal stewardship and customer service, TriMet will provide valued transit service that is safe, dependable, and easy to use by:

- $\quad$ Continuing to focus on rider needs

- Ensuring financial stability

- $\quad$ Strengthening the TriMet Team

- Meeting the transit needs of our growing region

Strategic Goals

1. Continue to focus on rider needs

- Improve service reliability and capacity

- Deliver service safely, efficiently and equitably

- $\quad$ Enhance the quality of the rider experience through information and amenities

2. Ensure Financial Stability

- $\quad$ Responsibly manage long-term liabilities

- $\quad$ Ensure a sustainable future for all employees and customers by providing employee benefits in line with peers

3. Strengthen the TriMet Team

- $\quad$ Continue to foster a culture of safety

- $\quad$ Provide employees the tools and training they need to succeed

- $\quad$ Engage all employees in finding ways to provide excellent service that results in positive customer experiences and perception 
4. Meet the transit needs of our growing region

- $\quad$ Provide service that supports current needs and future visions

- $\quad$ Advocate for more and better transit

- Work with partners to improve transit service and access and to advance projects

\section{TRI (a) MET}

Top Five Priorities for FY 2017

- $\quad$ Develop and execute a plan to scale up operators, vehicles and facilities to achieve the region's expectations for new service

- $\quad$ Negotiate a successor labor contract that allows TriMet to attract and retain a quality workforce while continuing to maintain its long-term financial stability.

- Deliver improved on-time performance through changes in infrastructure, process, procedures and development of people.

- Invest in an extended capital plan that ensures a state of good repair while supporting growth in the system, including the Powell-Division BRT and Southwest Corridor projects and successful eFare implementation.

- $\quad$ Execute a campaign to secure state and regional investment in transit and other transportation needs. 
Appendix C:

Interview Questions

Page 56 
Semi-structured interviews were held with TriMet staff from a range of positions traversing the organizational hierarchy over a three-day period in July 2016 in Portland, Oregon. A total of 19 employee group semi-structured interviews were conducted structured by working group. Using some of the interview questions (modified) from Keene \& Singh (2015) utilized for a proposed innovation framework for the Office of the Chief Corporate Officer at the City of Toronto, interview questions have been tailored to discussing innovation in the public sector as well as the specific questions focused on organizational structures and priorities. The questions are intended to elicit an explanation of their successes in innovation and continuous improvement and any opportunities for improvement.

The primary purpose of the semi-structured staff interviews was to understand the existing idea generation processes, communication, engagement and decision making structures that would inform a future innovation and continuous improvement framework for the agency. Two sets of interview questions were developed with one set for staff in professional roles (e.g., purchasing, communications, planning and policy) speaking to process and programs related to idea generation and to understand how decisions are made in the agency. A similar set of interview questions was created for front line staff (e.g., bus operators, customer service agents) that focused on how information is communicated to front line staff in the agency and how front line staff participate in engagement programs.

\section{Professional Staff Semi-Structured Interview Questions}

1. How would you describe the role of innovation in your organization?

2. Is innovation important to you? What is driving the need to innovate in your organization?

3. Describe how strategic planning occurs in your organization? How (or is) innovation integrated into this process?

4. Have you been involved in any employee engagement programs to provide your professional advice on programs, initiatives and policies?

5. How do you provide ideas and solutions for opportunities for continuous improvement in the organization?

6. Describe your current processes for encouraging or nurturing innovation within your organization. Discuss communication, training, internal employee engagement techniques, corporate initiatives etc.

7. How are community partnerships and academic collaborations encouraged in your organization? Is there a process to solicit and evaluate unsolicited ideas from community groups and academic institutions for continuous improvements of municipal services and initiatives? 
8. Describe one innovation project that you think was successful. What would you say are the key reasons for success? Describe one innovation project that was not successful. What were the key factors that contributed to this failure? How did your organization respond to the failure?

9. Innovations often start small - pilot projects, prototypes etc. but in order to maximize their potential, require scaling up in scope and size. Describe how you've experienced this in your organization?

10. What barriers are limiting more frequent, wide-spread innovation? What can be done to remove these barriers?

Front Line Staff Semi-Structured Interview Questions

1. What is your position with your agency/company? Please provide a brief description of your responsibilities?

2. How do you receive information about corporate initiatives and priorities?

3. Have you been involved in any employee engagement programs to provide your professional advice on programs, initiatives and policies?

4. How do you provide ideas and solutions for opportunities for continuous improvement in the organization?

5. How would you describe the role of innovation in your organization?

6. Are employees provided the resources (like training, time and autonomy) to innovate?

7. Given the context within your organization, what can senior leadership do to promote innovation?

8. Innovations often start small - pilot projects, prototypes etc. but in order to maximize their potential, require scaling up in scope and size. Describe how you've experienced this in your organization? 
Appendix D:

Sample of RTD BrightSpot 
Bright Spot of the Week:

Recruiting Mechanics

Bright

Spot Bright Spots are innovations that employees de-

WEEK velop to solve an issue within their workplace.

This week's bright spot comes from Mike Pekish (pictured) of Bus Maintenance, with assistance from Monica Caldwell-Reed, Victoria Broce, Travis Delsanno and Debra Lucero of Human Resources (HR).

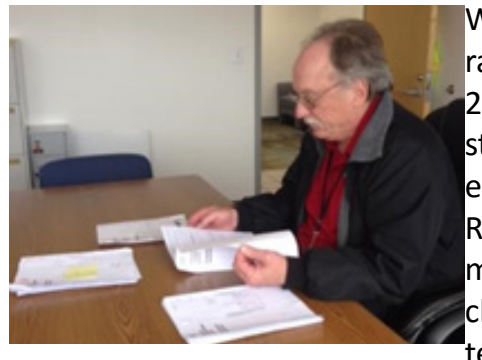

With Colorado's unemployment rate at less than $4 \%$ in 2015 and 2016, Bus Maintenance was struggling to recruit employees, especially mechanics. Because RTD has a critical need for mechanics and service and cleaning employees, bus maintenance management gave

Mike, an assistant manager, the opportunity to focus exclusively on recruiting to fill those positions starting in February of this year.

Back in September, Mike attended a Green Belt course, and he immediately put the tools he learned to use to improve recruitment for his department. First, Mike used a process map to identify all of the steps in the bus maintenance recruitment process in order to understand the current state. Using post-it notes, Mike listed every step of the process that Bus Maintenance oversaw, and he worked with Human Resources to fill in the gaps in his knowledge.

Next, Mike collaborated with Monica to identify opportunities for improvement. For example, in the past, when an application came in, HR and Bus Maintenance were only able to schedule a testing day approximately twice per week due to employee time constraints. This created a bottleneck for applicants. Mike recognized that bottleneck and is available for testing at almost any time that is convenient for the applicant - almost every day. Removing that bottleneck reduced waiting, one of the eight wastes, both for the applicant and the hiring manager.

Mike also worked with Bus Maintenance training and HR's Labor Relations group to make sure someone from each department was available for an interview right away for the candidates who passed the test.
That cut down on motion waste, or travel time, another one of the 8 wastes, since the job candidate can more often do both the test and the interview on the same day. While HR had been interviewing and testing on the same day whenever possible, the waiting in the first part of the process was creating overproduction later on - up to fifteen job candidates would take a test at one time, and it was sometimes impossible to interview everyone who passed the test on the same day.

Mike and Monica also streamlined the process after the interview. In the past, job candidates had to wait to receive a job offer instead of receiving it immediately after the interview. In addition, they would receive their instructions for the next steps in the process over the phone, which sometimes resulted in errors or defects, another one of the eight wastes. So Mike and Monica worked together to provide standard work to Bus Maintenance job candidates who passed both the test and the interview. The interviewers, including Mike, now give the successful job candidate a short checklist of tasks that the job candidate will need to complete in order to start work, such as drug testing and passing the DOT physical. Monica had already created a checklist for bus transportation job candidates, so it was relatively simple to replicate that bright spot in bus maintenance. Mike now hands the job candidate the checklist on the spot after the interview, so there's no need for a follow-up phone call. The checklist includes a date and location where they should report the Monday after the successful interview, so the job candidate knows exactly what they'll need to do to start work at RTD.

Each of Mike's improvements helped to cut down the recruitment time. Now most job candidates in Bus Maintenance are able to go from turning in an application to their first day on the job in under a month, and the process usually moves even faster than that.

For information on Green Belt training and other continuous improvement initiatives, contact John Elias x2476, Sarah Camacho $\times 6074$, or Rebecca Tate $x 6982$. 


\section{References}

Adams, A. (2015). Improving the customer experience at Calgary Transit. Major Research Paper. University of Victoria

Bason, C. (2010). Leading public sector innovation: Co-creating for a better society. Bristol, UK: The Policy Press

Brewer J. \& Hunter A. (2006). Foundations of multimethod research: synthesizing styles. Thousand Oaks, CA: Sage Publications

Booth, P. (2011). Culture, planning and path dependence: Some reflections on the problems of comparison. Town Planning Review, 82(1), 13-28.

Burns, T., \& Stalker, G. M. (1961). The management of innovation. London, UK: Tavistock.

City of Calgary. (2016). RouteAhead: A strategic plan for transit in Calgary. Retrieved August 2, 2016 from: https:// www.calgarytransit.com/plans-projects/plans

City of Denver. (2016a). Peak Academy main page. Retrieved July 17, 2016 from: https://www.denvergov.org/content/ denvergov/en/mayors-office/programs-initiatives/peak-performance/ peak-academy.html
City of Denver. (2016b). Denver Peak Academy: Black belt training presentation. Retrieved July 17, 2016 from: https://www.denvergov.org/content/ dam/denvergov/Portals/728/documents/Peak_Performance/Black_Belt/ Training_BlackBelt_Day1.pdf

Christensen, C.M. (2001). Assessing your organization's innovation capabilities. In Leader to Leader, 21: 27-37.

Deloitte. (2011). Innovation in government? Conversation with Canada's public service leaders. Retrieved July 25, 2016 from: http://www.ppforum. ca/sites/default/files/11-916G\%20 PS\%2OPPF-Innovation-Strategy-report-EN-WEB.pdf

Dougherty, D., \& Hardy, C. (1996). Sustained product innovation in large, mature organizations: Overcoming innovation-to-organization problems. Academy of Management Journal, 5(39), 1120-1153.

Fernandez, S. \& Rainey, H. (2006). Managing successful organizational change in the public sector. Public Administration Review, 66(2), 168-176. 
Fountain, J. E. (2001). Paradoxes of public sector customer service. Governance (Oxford), 14(1), 55-73.

Institute for Sustainable Communities. (2016). TriMet: Pioneering the field of open data. Retrieved July 25, 2016 from: http://sustainablecommunitiesleadershipacademy.org/resource_files/documents/TriMet-Portland-OR.pdf

Keene, C. \& Singh, M. (2015). Embedding innovation: how large organizations can succeed at innovation in the long term. Major Research Paper. OCAD University

King County. (2016). Introduction to Lean. Training Presentation

Klein, G. (2015). Start-up city: Inspiring private and public entrepreneurship,getting projects done and having fun. Washington, D.C.: Island Press.

Los Angeles Metro. (2016). Office of extraordinary innovation: Los Angeles regional investors conference. Retrieved July 17, 2016 from: http://cao.lacity.org/ debt/InvConf2016\%5C12.pdf

Moovel North America. (2016). Clients. Retrieved July 25, 2016 from: http:// www.moovel-transit.com/

Nagji, B. \& Tuff, G. (2012). Managing your innovation portfolio. Harvard Business Review. Retrieved July 14, 2016 from: https://hbr.org/2012/05/managing-your-innovation-portfolio
Needham, C. E. (2006). Customer care and the public service ethos. Public Administration (London), 84(4), 845-860.

Neuman, L. (2007). Basics of social research: qualitative and quantitative approaches. Boston, MA: Pearson Education

Regional Transportation District. (2015a). Best practices report. Retrieved July 28, 2016 from: http://www.rtd-denver.com/ documents/best-practices-2015.pdf

Regional Transportation District. (2015b). 2015-2020 RTD strategic plan. Retrieved July 17, 2016 from: http://www.rtd-denver.com/documents/2015-2020-strategic-plan.pdf

Senge, P. (1990). The fifth discipline: the art and practice of the learning organization. New York, NY. Doubleday Publishing

Singh, M. (2013). Innovation in the public sector. Independent Study. OCAD University

Shockley, G. E., Frank, P. M., \& Stough, R. R. (2008). Non-market entrepreneurship, interdisciplinary approaches. Cheltenham, UK: Edward Elgar Publishing Limited.

Thenint, H. (2010). Mini study 10: Innovation in the public sector. Retrieved July 14, 2016 from: http://grips.proinno-europe.eu/knowledge_base/dl/889/ orig_doc_file/ 
Transit Cooperative Research Program. (2000). TCRP report 58: New paradigms for local public transportation organizations. Washington, D.C.: Transportation Research Board.

Transit Cooperative Research Program. (2003). TCRP report 97: Emerging new paradigm: A guide to fundamental change in local public transportation organizations. Washington, D.C.: Transportation Research Board.

Transit Cooperative Research Program. (2005). TCRP synthesis 59: Strategic planning and management in transit agencies. Washington, D.C.: Transportation Research Board.

TriMet. (n.d.). Policy and rules concerning the receipt and award of contracts pursuant to unsolicited proposals for public-private partnership infrastructure projects. Retrieved July 25, 2016 from: https://trimet.org/pdfs/procurement/ unsolicited-proposal-policy.pdf

TriMet. (2002). Productivity improvement process summary January 2001July 2002.

TriMet. (2003). Productivity improvement process: Working smarter, transforming a culture.

TriMet. (2014). TriMet five year action plan lead assignments.
TriMet. (2015a). TriMet's five-year action plan FY2015 - FY2019

TriMet. (2015b). Portland-Milwaukie light rail transit project sustainability report: Making the orange line green. Retrieved July 25, 2016 from: http://trimet. org/orangeline/pdf/sustainability-report.pdf

TriMet. (2016a). TriMet at a glance. Retrieved July 25, 2016 from: http://trimet. org/ataglance/

TriMet. (2016b). TriMet organizational governance. Retrieved July 25, 2016 from: https://trimet.org/about/governance.htm

TriMet. (2016c). Engagement at TriMet. Quantum Workplace.

Utah Transit Authority. (2015). Year in review 2014. Retrieved July 20, 2016 from: https://www.rideuta.com/uploads/UTAYearinReview2014.pdf

Utah Transit Authority. (2016a). Introduction to continuous improvement. Training Presentation.

Utah Transit Authority. (2016b). Living the UTA way.

Utah Transit Authority. (2016c). Introduction to the voice of the customer, business \& process. Training Presentation. 
Images

All images of TriMet staff, vehicles and facilities are courtesy of TriMet and have been used with permission from the TriMet Flickr page located at: https://www.flickr.com/photos/trimet/

\section{Appendices}

Appendix A: TriMet Organizational Structure TriMet. (2016b). TriMet organizational governance. Retrieved July 25, 2016 from: https://trimet.org/about/governance.htm

Appendix B: TriMet Five Year Strategic Goals

TriMet. (2015a). TriMet's five-year action plan FY2015 - FY2019

Appendix C: Interview Questions

Appendix D: Sample of RTD BrightSpot Regional Transportation District. (2016, May 23) Bright Spot of the Week: Recruiting mechanics. Monday Morning $\mathrm{O}$. 